Check for updates

Cite this: J. Mater. Chem. B, 2019, 7, 5376

\section{Autophagy-dependent toxicity of amino-functionalized nanoparticles in ovarian cancer cells $\dagger$}

\author{
Christian Seca, $\ddagger^{\mathrm{a}}$ Alessandra Ferraresi, $\stackrel{\ddagger}{\mathrm{t}}^{\mathrm{a}}$ Suratchanee Phadngam, ${ }^{\text {ab }}$ Chiara Vidoni $^{\mathrm{a}}$ \\ and Ciro Isidoro (iD) *a
}

\begin{abstract}
The use of nanoparticles (NPs) for diagnostic and therapeutic purposes involves the risk of side effects due to the presence of reactive groups on their surface. We studied the cellular stress response to spheroid fluorescent polystyrene nanoparticles (PS-NPs) functionalized with Amino groups in two ovarian cancer cell lines differing in the expression, among others, of relevant proteins involved in endocytosis processes (Caveolin-1) and in pro-survival/pro-death pathways (PTEN and p53). While COOH-PS-NPs were not toxic, $\mathrm{NH}_{2}$-PS-NPs showed dose- and time-dependent toxicity along with the induction of autophagy. In OVCAR3 cells, which are PTEN and P53 mutated and deficient in CAV-1, autophagy was insufficient to protect the cells from NP toxicity. Accordingly, inducers of autophagy were prevented whereas the silencing of autophagy genes exacerbated NP toxicity. In contrast, in OAW42 cells, which express wildtype PTEN, P53 and CAV-1, NH 2 -PS-NPs strongly limited the formation of autophagosomes, along with an increased production of the mitochondrial anion superoxide and inactivation of ATG4. Preventing the production of the mitochondrial anion superoxide rescued ATG4-mediated autophagy and saved the cells. This study outlines the relevance of the genetic background in the autophagy response to toxicity provoked by $\mathrm{NH}_{2}$-functionalized PS-NPs in cancer cells.
\end{abstract}

Received 9th May 2019,

Accepted 29th July 2019

DOI: 10.1039/c9tb00935c

rsc.li/materials-b
Besides, the biological effects vary among the cell types. ${ }^{14}$ The biological responses to NPs include prompt extrusion, ${ }^{12,15,16}$ re-localization in other compartments, ${ }^{16-19}$ production of ROS, ${ }^{20,21}$ cell cycle arrest, ${ }^{22,23}$ cell death and autophagy. ${ }^{24-28}$ The role of autophagy and the cellular and molecular mechanisms involved in the toxicity elicited in vivo and in vitro by NPs of different size, charge and material have recently been reviewed..$^{29,30}$ Autophagy is a lysosome-driven catabolic process that maintains cellular homeostasis by degrading harmful molecules, organelles, particles and excessive or redundant self-materials. ${ }^{31}$ It is a stress response triggered by metabolic imbalance, xenomaterial and oxidative stress. ${ }^{32}$ Autophagy starts with the formation of a double-membrane vacuole (called autophagosome) that entraps the material to be degraded. Characteristically, both the inner and outer membranes of the autophagosome are decorated with phosphatidyl-ethanolamineconjugated Light Chain 3 (so-called LC3-II isoform), a protein that is derived from the processing of a microtubule-associated precursor (MAP-LC3). ${ }^{33}$ The autophagy substrate is selectively internalized in the forming autophagosome, thanks to the bridge between the ubiquitin like p62/SQSTM1 and LC3. ${ }^{34}$ The autophagosome eventually fuses with lysosomes to form an autolysosome, in which the autophagy substrate is degraded by the acidic hydrolases along with p62/SQSTM1. ${ }^{31}$ As a controller 
of cell metabolism and tissue homeostasis, autophagy plays a prominent role in cancer development and progression. ${ }^{35}$

Ovarian cancer is the most malignant and aggressive gynecologic cancer, claiming each year almost 150000 deaths among the affected women in the world (https://seer.cancer.gov/stat facts/html/ovary.html). Autophagy is involved in ovarian cancer development and progression. ${ }^{36,37}$ In principle, nanotheranostics could exploit autophagy for therapeutic purposes in ovarian cancer. ${ }^{25}$ In this work, we investigated the regulation and the role of autophagy and ROS production in the cell death pathways triggered by amino-functionalized (cationic) polystyrene NPs ( $\mathrm{NH}_{2}$-PS-NPs) in ovarian cancer cells. To test the relevance of the genetic background in the toxic response of cancer cells versus these NPs, we employed two ovarian cancer cell lines, OAW42 and OVCAR3, differing in CAV-1, PTEN and TP53 genes, among others. The involvement and actual role of autophagy in the stress and toxic responses were investigated through pharmacologic and genetic manipulations. The aims and experimental design are illustrated in the ESI, $\dagger$ Fig. S1. Though causing necrotic death in both cell types, we demonstrate the different effect of $\mathrm{NH}_{2}$-PS-NPs on the autophagy machinery. To the best of our knowledge, this is the first study showing the inactivation of ATG4, a protein fundamental to the generation of autophagosomes, by $\mathrm{NH}_{2}$-PS-NPs. We also demonstrate that this effect is due to the over-production of the mitochondrial ROS and that it can be reverted by resveratrol, a polyphenol known for its anti-oxidant and anticancer properties.

\section{Material and methods}

\section{Cell culture}

Human ovarian cancer OVCAR3 and OAW42 cell lines were obtained from ATCC (http://www.lgcstandards-atcc.org) and cultured under standard conditions $\left(37{ }^{\circ} \mathrm{C}, 5 \% \mathrm{CO}_{2}\right)$ in RPMI 1640 (cod. R8758) or MEM (cod. M2279) medium, respectively, supplemented with 10\% heat-inactivated FBS (cod. ECS0180L; Euroclone Spa, Milano, Italy), 1\% Glutamine (cod. G7513), 1\% non-essential amino acids (cod. M7145) and 1\% penicillin and streptomycin (cod. P0781). Culture media and supplements were purchased from Sigma Aldrich (Saint Louis, Missouri, USA).

\section{Reagents}

Chloroquine (ClQ, cod. C6628; Sigma Aldrich) was dissolved in sterile water and used at a final concentration of $30 \mu \mathrm{M}$. Rapamycin (Rap, cod. R8781; Sigma Aldrich) was dissolved in DMSO and used at a $1 \mu \mathrm{M}$ final concentration. Metformin (Met, cod. D150959; Sigma Aldrich) was dissolved in sterile water and used at a $5 \mathrm{mM}$ final concentration. The pan-caspases inhibitor z-VAD (OMe)-fmk (z-VAD-fmk, cod. 260-020-M005, Alexis Laboratories, Farmingdale, NY, USA) was dissolved in DMSO and used at a $20 \mu \mathrm{M}$ final concentration. DMSO (final concentration $0.01 \%$ ) had no effect on cell growth and autophagy. Resveratrol (RV, cod. R5010, Sigma Aldrich) was used at a $100 \mu \mathrm{M}$ final concentration. Oxalyplatin (cod. 13106, Cayman Chemical Company, Ann Arbor, MI, USA) was used at a $50 \mu \mathrm{M}$ final concentration.

\section{Primary antibodies}

The following antibodies were used: rabbit anti-LC3 (for WB 1 : 1000; cod. L7543, Sigma Aldrich), mouse anti-LC3 (for IF 1 :100; cod. 0231-100/LC3-5F10, Nanotools, Teningen, Germany), rabbit anti-ATG4 (for WB 1:500, for IF 1:200; cod. 7613, Cell Signaling, Danvers, MA, USA), mouse anti- $\beta$-tubulin $(1: 1000$; cod. T5201, Sigma Aldrich), rabbit anti-p-AKT (Ser473) (1:500; cod. 9271, Cell Signaling), rabbit anti-AKT (1:500; cod. 4685, Cell Signaling), rabbit anti-p-S6 (Ser235/236) (1:500; cod. 4856, Cell Signaling), rabbit anti-S6 (1:500; cod. 2217, Cell Signaling), rabbit anti-p-AMPK (Thr172) (1:500; cod. 2535, Cell Signaling), rabbit anti-AMPK (1:500; cod. 2532, Cell Signaling), rabbit anti-p62/ SQTM1 (1:500; cod. 8025, Cell Signaling), mouse anti-LAMP1 (1:1000; cod. 555798, BD, Becton, Dickinson and Company, New Jersey, NJ, USA), rabbit anti-BAX (1:500; cod. 2774, Cell Signaling).

\section{Nanoparticles and $Z$ potential measurement}

The following commercial polystyrene nanoparticles (PS-NPs) were purchased from Sigma Aldrich: $30 \mathrm{~nm}$ diameter, carboxyfunctionalized (COOH-PS-NPs), green color emitting (cod. L5155); $50 \mathrm{~nm}$ diameter, amine-functionalized $\left(\mathrm{NH}_{2}\right.$-PS-NPs), blue color emitting (cod. L0780). The zeta potential of the NPs has been determined in water suspensions at $25{ }^{\circ} \mathrm{C}$ by using a Malvern Zetasizer NanoZS Instrument (Malvern Panalytical, UK) equipped with a He-Ne laser with a length of $633 \mathrm{~nm}$. The values were as follows: $\mathrm{NH}_{2}$-PS-NPs $=+37.1 \pm 7.9 \mathrm{mV}$; COOH-PS-NPs $=-56.7 \pm$ $4.7 \mathrm{mV}$. Similarly, an independent measurement made in a different laboratory gave the following: $\mathrm{NH}_{2}$-PS-NPs $=+35.4 \pm$ $1.96 \mathrm{mV}$; COOH-PS-NPs $=-52.6 \pm 1.82 \mathrm{mV}$. The $Z$ potential measured in saline buffer was $+17.4 \pm 2.19 \mathrm{mV}$ for the former and $-33 \pm 0.964$ for the latter.

\section{Endocytosis studies}

Cells were plated on sterile coverslips and left to adhere for 24 hours, then the medium was replaced, and cells were incubated with the PS-NPs for the time indicated. To trace the endocytic pathway, the cells were pre-labeled 10 minutes before the end of the treatment with $100 \mathrm{nM}$ LysoTracker Red probe (cod. L7528, Life Technologies Ltd, Paisley, UK). Coverslips were washed, mounted and immediately imaged under the microscope.

\section{Cell tracker staining}

Cells plated on sterile coverslips and treated with the PS-NPs as indicated and labeled with the fluorescent dye CellTracker ${ }^{\mathrm{TM}}$ (CellTracker $^{\mathrm{TM}}$ Blue-CMAC 7-amino-4-chloromethylcoumarin; cod. C2110, Life Technologies Ltd) as previously reported. ${ }^{38}$ At the end of treatment, fluorescent dye stained coverslips were promptly observed using the fluorescence microscope.

\section{Propidium iodide staining}

Cells plated on sterile coverslips were treated as indicated. Necrotic cells were detected by using $0.2 \mu \mathrm{g} \mathrm{ml}^{-1}$ propidium iodide (PI; incubation for $10 \mathrm{~min}$ in the dark at $37{ }^{\circ} \mathrm{C}$; cod. $\mathrm{P} 4170$, Sigma Aldrich). At the end of treatment, fluorescent dye 
stained coverslips were promptly observed using the fluorescence microscope.

\section{Assessment of anion superoxide production by MitoSOX staining}

Cells plated on sterile coverslips were treated as indicated. Mitochondrial superoxide anions were detected in living cells by using $5 \mu \mathrm{M}$ MitoSOX-red probe (cod. M36008, Life Technologies Ltd; incubation for $10 \mathrm{~min}$ in the dark at $37{ }^{\circ} \mathrm{C}$ ). At the end of treatment, fluorescent dye stained coverslips were promptly observed using the fluorescence microscope.

\section{Immunofluorescence}

The cells plated on sterile coverslips were treated as indicated and processed for immunofluorescence staining. After cell fixation with ice-cold methanol and permeabilization with $0.2 \%$ TritonPBS, coverslips were incubated with specific primary antibodies overnight at $4{ }^{\circ} \mathrm{C}$ (diluted in $0.1 \%$ Triton-PBS $+10 \%$ FBS). The following day, coverslips were incubated with dye-conjugated secondary antibodies (diluted in $0.1 \%$ Triton-PBS $+10 \%$ FBS) for 1 hour at room temperature $\left(20-22{ }^{\circ} \mathrm{C}\right)$. The following secondary antibodies were employed: either IRIS-2 (green fluorescence)- or IRIS-3 (red fluorescence)-conjugated goatanti rabbit IgG or goat-anti mouse IgG (cod. 2W5-08, cod. 2w5-07, cod. 3w5-08, cod. 3w5-07; Cyanine Technology, Torino, Italy), as appropriate. Nuclei were stained with the UV fluorescent dye DAPI (4',6-diamidino-2-phenylindole; cod. 32670, Sigma Aldrich). Coverslips were mounted onto glass using the SlowFade anti-fade reagent (cod. S36936; Life Technologies, Milan, Italy) and imaged under the fluorescence microscope.

\section{Transfection of the GFP-LC3 plasmid}

Cells were transfected with GFP-LC3 plasmid using lipofectamine 3000 Reagent (cod. L3000-015, Life Technologies), as indicated by the purchaser. Briefly, OVCAR3 and OAW42 cells were plated on coverslips at the density of $30000-40000 \mathrm{~cm}^{-2}$ and left to adhere for 24 hours before transfection. The DNA loaded liposomal complexes were prepared in Opti-MEM I Reduced Serum Medium (cod. 11058021, Life Technologies) with $6 \mu \mathrm{g}$ of plasmid, $5 \mu \mathrm{l}$ of p3000 reagent and $7.5 \mu \mathrm{l}$ of lipofectamine 3000. After 6 hours of incubation, the medium was replaced with complete serumcontaining culture medium (10\% FBS), and the cells were cultivated for a further 24 hours to allow the maximal expression of the transgenic protein prior to any treatment. The plasmid construct has been reported previously. ${ }^{39}$

\section{Imaging acquisition and analysis}

Fluorescence images were acquired on a Leica DMI600 multichannel fluorescence microscope (Leica Microsystems, Wetzlar, Germany; DMI6000) equipped with motorized focus Z-stacking. For each experimental condition, at least three slides were prepared in separate experiments and six to ten microscopic fields randomly chosen were imaged by two independent investigators unaware of the treatment. At least 100 to 150 cells were considered in total. Quantification of fluorescence intensity was performed using the software ImageJ. Representative images of selected fields are shown.

\section{Autophagy gene silencing}

Post-transcriptional silencing was achieved by using the small interference RNA (siRNA) technology. Cells were transfected with siRNA $A T G 7$, siRNA BECLIN-1 or siRNA scrambled using lipofectamine 3000 Reagent (cod. L3000-015, Life Technologies) as indicated by the purchaser. The oligonucleotide sequences for the scramble and siRNA BECLIN-1 have been reported previously. ${ }^{39}$ The sequence for siRNA $A T G 7$ was as follows: $5^{\prime}$-GGG UUA UUA CUA CAA UGG UGT T- $3^{\prime}$.

The cells were plated on coverslips and left to adhere for 24 hours before transfection. The DNA loaded liposomal complexes were prepared in Opti-MEM I Reduced Serum Medium (cod. 11058021, Life Technologies) with 100 pmol of siRNA and $7.5 \mu \mathrm{l}$ of lipofectamine 3000. After 6 hours, the medium was replaced with complete serum-containing culture medium (10\% FBS), and the cells were cultivated for a further 24 hours to allow the maximal gene silencing prior to any treatment. Thereafter, cells were treated with NPs. The coverslips were stained with propidium iodide and processed as described above.

\section{Western blotting}

Cells were seeded in p35 Petri dishes at the cell density of 40000-50000 cell per $\mathrm{cm}^{2}$ and cultured up to approximately $80 \%$ of confluence. Cells were washed once with PBS $1 \mathrm{X}$ and harvested with lysis buffer containing $0.2 \%$ NADOC and supplemented with protease inhibitor cocktail and phosphatase inhibitors (50 mM NaF and $1 \mu \mathrm{M} \mathrm{Na}_{3} \mathrm{VO}_{4}$ ). Bradford assay was used to measure the protein content. Equal amounts of cell homogenates $(30 \mu \mathrm{g})$ were denatured with Laemmli sample buffer at $95{ }^{\circ} \mathrm{C}$ for $10 \mathrm{~min}$, resolved by SDS-PAGE and thereafter blotted onto the PVDF membrane. The membranes were blocked with $5 \%$ non-fat dry milk $+0.2 \%$ Tween for 1 hour at room temperature, and thereafter incubated with primary antibodies overnight at $4{ }^{\circ} \mathrm{C}$. The following day, the membranes were washed and incubated with the secondary antibody (Goat anti-mouse (cod. 170-6516) or Goat anti-rabbit (cod. 170-6515); Bio-Rad, Hercules, CA, USA) for 1 hour at room temperature (20-22 $\left.{ }^{\circ} \mathrm{C}\right)$. The membranes were washed, and the bands were detected by using Enhanced Chemiluminescent reagents (ECL; cod. NEL105001EA; PerkinElmer Inc., Waltham, MA, USA) and imaged using the VersaDOC Imaging System. For loading control, the membranes were re-probed with $\beta$-tubulin or $\beta$-actin. Intensity of the bands was estimated via densitometry using Quantity One software.

\section{Statistical analysis}

Statistical analysis was performed using the GraphPad Prism 5.0 software. The Bonferroni's multiple comparison test after one-way ANOVA analysis (unpaired, two-tailed) was employed. Significance was considered as follows: ${ }^{* * *} p<0.0001$; ${ }^{* * *} p<0.001 ;{ }^{* *} p<0.01 ;{ }^{*} p<0.05$. All experiments have been reproduced at least three times in separate and independent replicates. All data are reported as average \pm S.D. 


\section{Results}

1. $\mathbf{N H}_{2}$-PS-NPs induce caspase-independent necrotic cell death in ovarian cancer cells

In the first set of experiments, the cells were incubated for increasing times with two doses of PS-NPs and uptake and toxicity were assessed by fluorescence visualization. Images shown (in the ESI, $\dagger$ Fig. S2A) indicate that both $\mathrm{COOH}_{-}$ or $\mathrm{NH}_{2}$-functionalized PS-NPs were initially up-taken via the endocytic pathway labeled with Lysotracker and thereafter redistributed in the cytoplasm. As indicated by Cell Tracker staining (ESI $\dagger$ Fig. S2), $50 \mu \mathrm{g} \mathrm{ml}^{-1}$ COOH-PS-NPs (anionic charged) was not toxic to either OAW42 or OVCAR3 cells when incubated for up to $24 \mathrm{~h}$, whereas 25 and $50 \mu \mathrm{g} \mathrm{ml}{ }^{-1} \mathrm{NH}_{2}$-PSNPs (cationic charged) were revealed to be toxic for both cell types. Toxicity was slightly apparent at $6 \mathrm{~h}$ and extensive at $24 \mathrm{~h}$ when the cells were exposed to $50 \mu \mathrm{g} \mathrm{ml}^{-1} \mathrm{NH}_{2}$-PS-NPs (Fig. S2B, ESI $\dagger$ ). This prompted us to further investigate the toxic mechanisms of $\mathrm{NH}_{2}$-PS-NPs in the two cell types. To assay whether toxicity resulted from apoptosis and/or necrosis, the cells were incubated with 25 and $50 \mu \mathrm{g} \mathrm{ml}{ }^{-1} \mathrm{NH}_{2}$-PS-NPs for $16 \mathrm{~h}$ in the absence or the presence of the pan-caspase inhibitor zVAD-fmk. The cells were then directly (without prior fixation) stained with propidium iodide (that stains the DNA of necrotic cells) and immediately imaged under the fluorescence microscope. The images in Fig. 1 indicate that $\mathrm{NH}_{2}$-PS-NPs induced a caspase-independent necrotic-type death in both cell types. As proof that the apoptotic machinery was effective in these cells, we checked for the induction of BAX oligomerization ${ }^{40}$ upon exposure to oxalyplatin, a drug widely used in the chemotherapy of ovarian cancers. The images in Fig. S3 (ESI $\dagger$ ) show that in both OVCAR3 and OAW42 cells, this drug, but not $\mathrm{NH}_{2}$-PS-NPs, triggers BAX-mediated apoptosis.

\section{2. $\mathbf{N H}_{2}$-PS-NPs induce the autophagy flux in OVCAR3 cells}

We employed GFP-LC3 expressing cells to investigate whether autophagy was triggered as a stress response to $\mathrm{NH}_{2}$-PS-NPs.

\section{A}
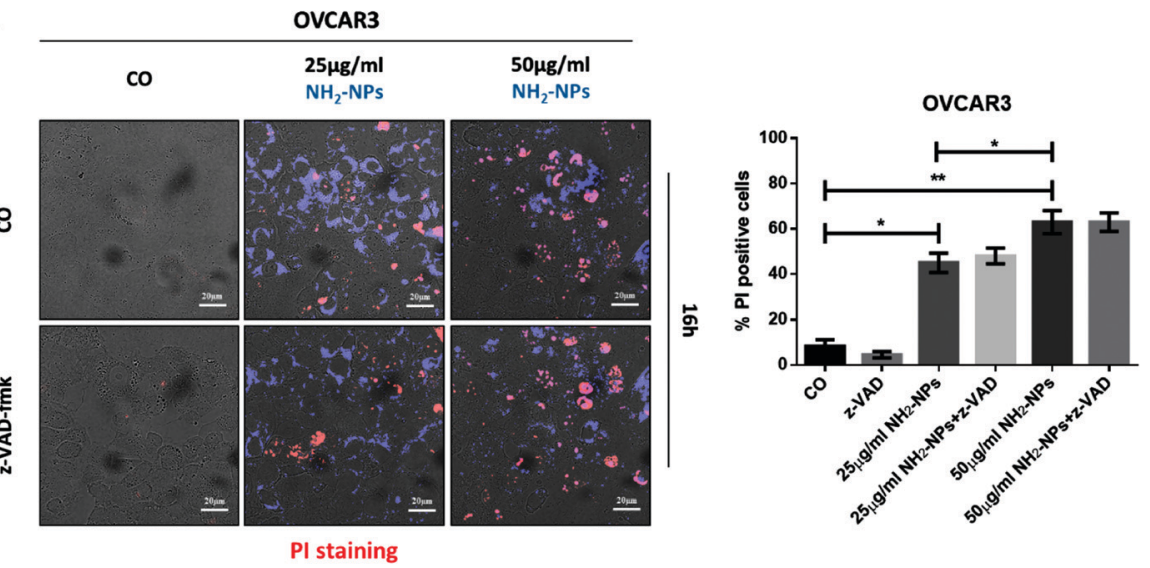

B
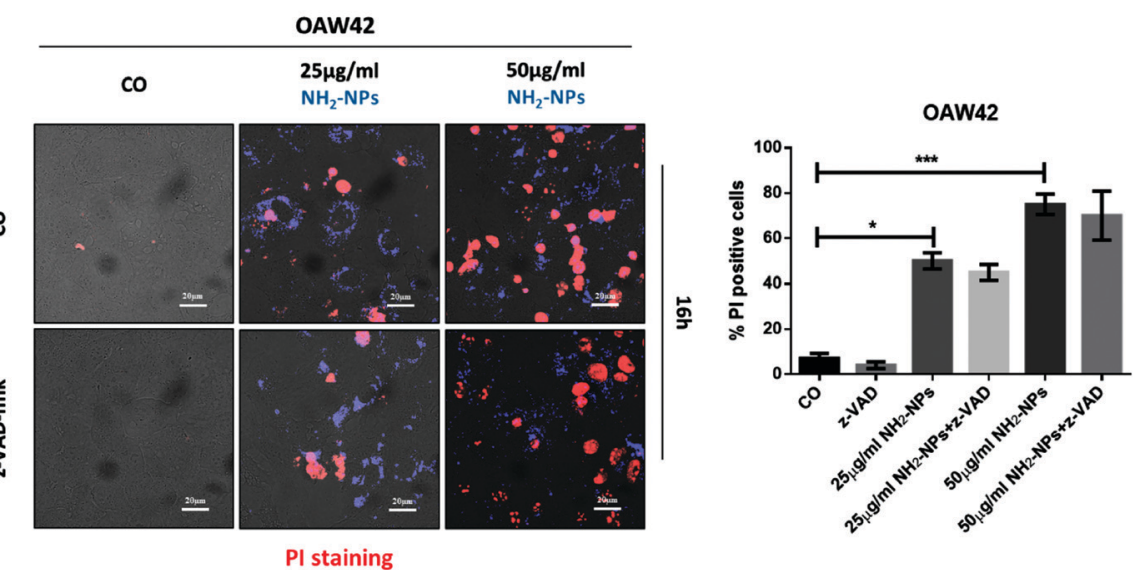

Fig. $1 \mathrm{NH}_{2}$-PS-NPs induce caspase-independent necrotic-type cell death. Cells were plated on sterile coverslips and left to adhere for 24 hours. Then, cells were incubated without (CO, control) or with $25 \mu \mathrm{g} \mathrm{ml}^{-1}$ or $50 \mu \mathrm{g} \mathrm{ml}^{-1} \mathrm{NH}_{2}$-NPs in the presence/absence of the pan-caspase inhibitor z-VAD-fmk for 16 hours. Propidium iodide (PI) was added 10 minutes before the end of the treatment and incubated at $37^{\circ} \mathrm{C}$ in the dark. Coverslips were washed and mounted on glass and imaged immediately on the fluorescence microscope. Staining was performed in OVCAR3 cells (A) and in OAW42 cells (B). Cell death was assessed by counting the percentage of PI positive cells and is represented in the histograms (\% \pm SD). On average, a minimum of $100-150$ cells were counted in randomly chosen fields by two independent investigators. Significance was considered as follows: $\star \star \star p ~<0.001$; ${ }^{* *} p<0.01 ;{ }^{*} p<0.05$. All experiments have been reproduced at least three times in independent replicates. 
In control cells not exposed to NPs, GFP fluorescence is diffused in the cytoplasm (as expected when autophagy is not active), while upon exposure to NPs, GFP fluorescence is scattered in spots indicative of LC3 recruitment in the membranes of autophagosomes (Fig. 2A). A large portion of GFP spots overlapped with blue fluorescence, suggestive of co-localization of $\mathrm{NH}_{2}$-PS-NPs with autophagosomes (Fig. 2A, merged channels). To further substantiate the induction of autophagy by the NPs, the cells were fixed and immunostained for LC3 and ATG4 (the latter is the cysteine protease that processes LC3-I). As shown in Fig. 2B, the expression and the co-localization of LC3 and ATG4 were greatly stimulated in the cells exposed to $\mathrm{NH}_{2}$-PS-NPs. In addition, the level of p62/SQSTM1 decreased in the cells exposed to the NPs, indicative of stimulation of the autophagy flux (Fig. 2C). It should be noted that in control cells, p62 localizes in the cytoplasm, as indicated by the lack of co-localization with the lysosomal marker LAMP1 (Fig. 2C). To definitively prove the induction of autophagosomes by $\mathrm{NH}_{2}$-PS-NPs, the homogenate of cells incubated with NPs was used to assay the conversion of LC3-I into LC3-II by western blotting. In this experiment, chloroquine (ClQ)

A

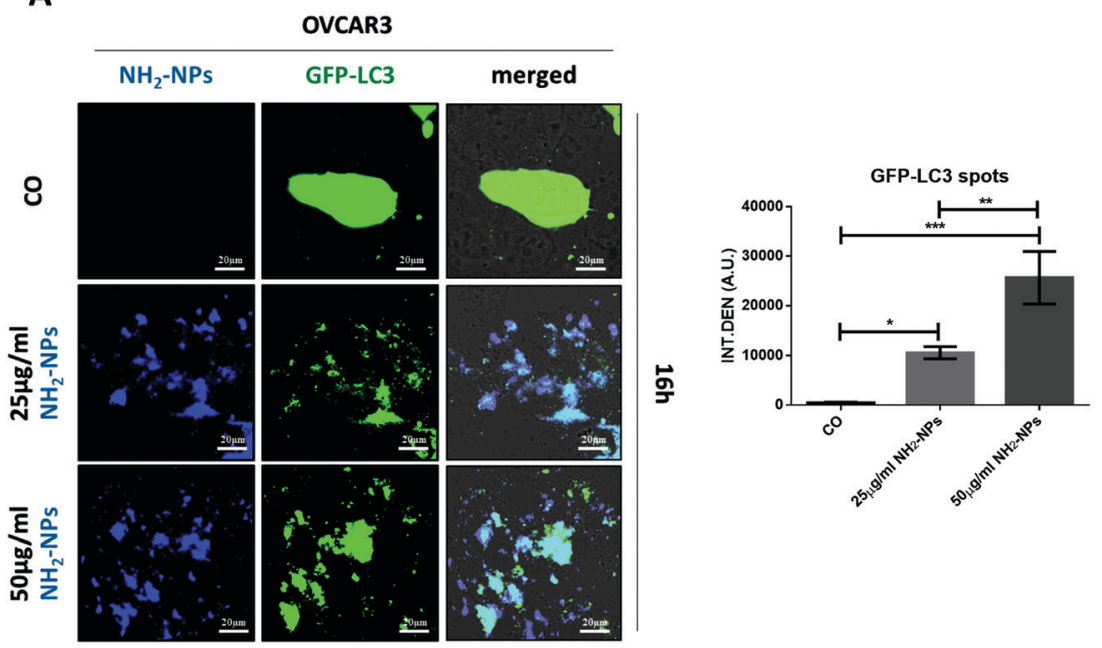

B

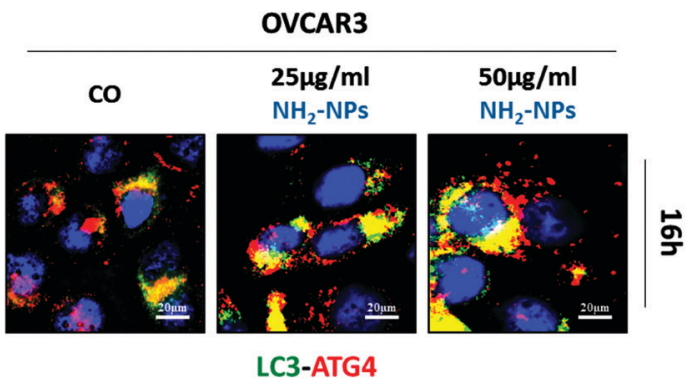

C

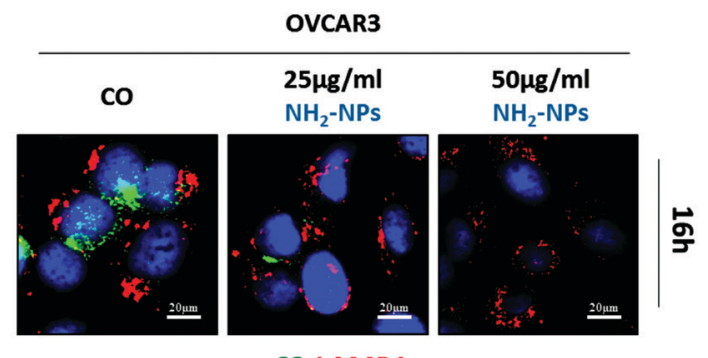

p62-LAMP1

Fig. $2 \mathrm{NH}_{2}$-PS-NP toxicity in OVCAR3 cells associated with increased autophagy. OVCAR3 cells were plated on sterile coverslips and left to adhere.

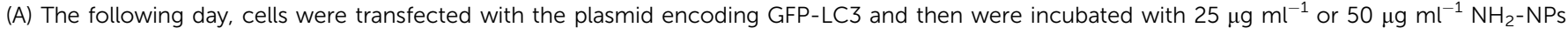
for 16 hours. Control (CO) cells were not exposed to the NPs. Autophagy induction was quantified by counting GFP-LC3 spots by using ImageJ software. Data representing three independent experiments are reported in the histogram as an average (A.U. \pm SD). Significance was considered as follows: ${ }^{* \star *} p<0.001 ;{ }^{* *} p<0.01 ;{ }^{*} p<0.05$. (B) Cells were incubated without (CO, control) or with $25 \mu \mathrm{g} \mathrm{ml} \mathrm{l}^{-1}$ or $50 \mu \mathrm{g} \mathrm{ml}{ }^{-1} \mathrm{NH}_{2}-\mathrm{NPs}_{\text {for }} 16$ hours. Coverslips were immunofluorescence double stained for LC3 (green) and ATG4 (red). (C) Cells were treated as in panel C and the coverslips were immunofluorescence double stained for p62 (green) and LAMP1 (red). Images are representative of three independent experiments. 
was included to discriminate between the newly produced and accumulated undegraded LC3-II. ${ }^{41}$ Data in Fig. 3A demonstrate the increased accumulation of newly produced LC3-II in the cells exposed to $\mathrm{NH}_{2}$-PS-NPs. Further, the expression of ATG4 also increased upon exposure to the NPs (Fig. 3B). Finally, we analyzed the expression and activation status of the two major pathways controlling autophagy and cell survival under stress, i.e. the AKT-mTOR and AMPK pathways. The data shown in Fig. S4 (ESI $\dagger$ ) indicated that $\mathrm{NH}_{2}$-PS-NPs switch off the AKT-mTOR pathway and switch on the AMPK pathway, consistent with the induction of autophagy as a stress response. Taken together, these data confirm the induction of autophagy and of the autophagy flux by $\mathrm{NH}_{2}$-PS-NPs in OVCAR3 cells.

\section{Genetic inhibition of autophagy exacerbates whereas} pharmacologic enhancement of autophagy prevents $\mathrm{NH}_{2}$-PS-NP toxicity in OVCAR3 cells

Next, we investigated the functional role of autophagy in the cells exposed to $\mathrm{NH}_{2}$-PS-NPs. To this end, we manipulated the intrinsic level of autophagy and tested the cytotoxic response to $\mathrm{NH}_{2}$-PS-NPs. First, we silenced two autophagy-related (ATG) genes, namely BECLIN-1 and ATG7, and then exposed the cells to $\mathrm{NH}_{2}$-PS-NPs and assayed cell death by PI staining. As shown in Fig. 4, in the ATG-specific siRNA-transfected cultures, the number of PI-positive necrotic cells was much higher than in control sham-transfected cultures. The efficient gene silencing and down-regulation of autophagy in the cells transfected with

A

OVCAR3 16h
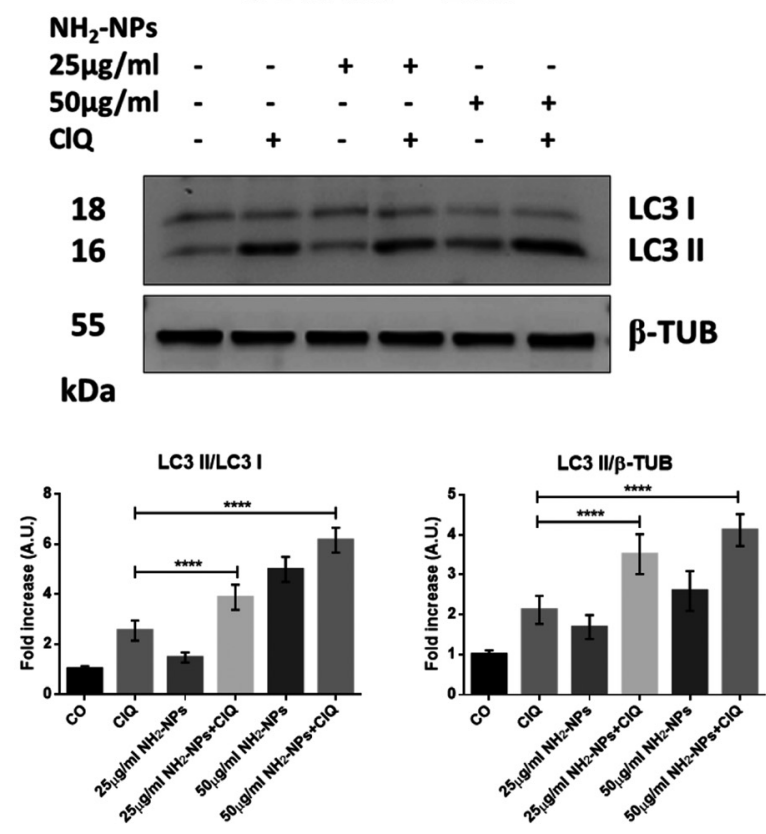

B

OVCAR3 16h
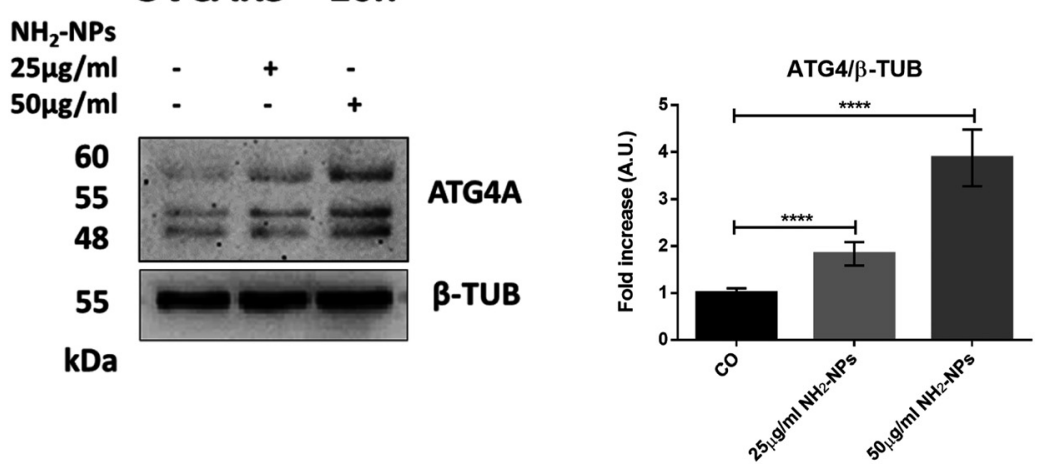

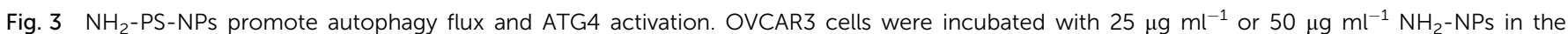
presence/absence of chloroquine (CIQ) for 16 hours. (A) Autophagy flux modulation was monitored by following the LC3-I to LC3-II conversion. (B) ATG4 expression levels were assessed by Western Blotting. Densitometric analyses of LC3 (upper panel) and of ATG4 (lower panel) were performed using QuantityOne software. Data are presented in the histograms as an average (in A.U., arbitrary units) \pm SD. All data are representative of three independent experiments. Significance was considered as follows: ${ }^{* \star *} p<0.0001$. 

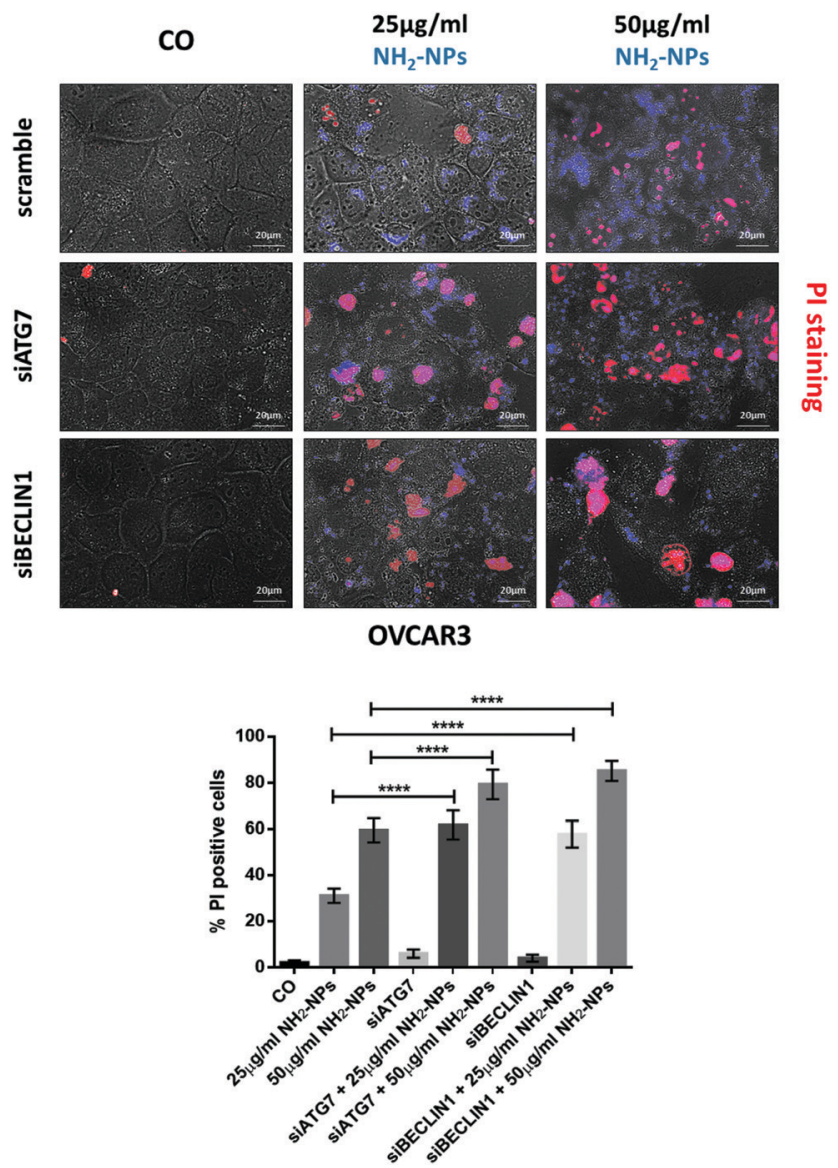

Fig. 4 Silencing of autophagy genes exacerbates $\mathrm{NH}_{2}$-PS-NP toxicity in OVCAR3 cells. OVCAR3 cells were transfected with siATG7 or siBECLIN-1 for 36 hours and incubated without (CO, control) or with $25 \mu \mathrm{g} \mathrm{ml}^{-1}$ or $50 \mu \mathrm{g} \mathrm{ml}^{-1} \mathrm{NH}_{2}-\mathrm{NPs}$ for 16 hours. At the end of the treatment, propidium iodide (PI) staining was performed. Coverslips were washed, mounted and immediately imaged using the fluorescence microscope. Necrosis was assessed by counting the percentage of PI positive cells and the quantification is presented in the histogram $(\% \pm S D)$. On average, a minimum of 100-150 cells were counted in randomly chosen fields by two independent investigators. Significance was considered as follows: ${ }^{* \star *} p<0.0001$. All experiments have been reproduced at least three times in independent replicates.

SiRNA BECLIN-1 or SiRNA ATG7 were ascertained in parallel cultures (not shown).

In a second set of experiments, we stimulated autophagy by treating the cells with rapamycin, an inhibitor of mTORC1, ${ }^{42}$ or with metformin, an inducer of the AMPK pathway. ${ }^{43}$ These drugs effectively enhanced the intrinsic level of autophagy, as demonstrated by the increased expression and co-localization of LC3 and ATG4 and concomitant reduced accumulation of p62 (Fig. 5A and B). Upon exposure to $\mathrm{NH}_{2}$-PS-NPs, the number of PI-positive necrotic cells found in the rapamycinor metformin-treated cultures was much lower than that in the untreated culture exposed to the same concentration and for the same period to the NPs (Fig. 5C). Taken together, these data indicate that in OVCAR3 cells, the $\mathrm{NH}_{2}$-PS-NPs induce prosurvival autophagy, which is however insufficient to prevent toxicity.

\section{4. $\mathrm{NH}_{2}$-PS-NPs inhibit the formation of autophagosomes in} OAW42 cells

Next, we checked whether $\mathrm{NH}_{2}$-PS-NPs elicited similar modulatory effects on autophagy in OAW42 cells. To our surprise, in these cells, $\mathrm{NH}_{2}$-PS-NPs instead inhibited autophagy, more particularly at the very early step of autophagosome formation. This was evident in cells transiently expressing the GFP-LC3 chimeric protein (Fig. 6A) and by immunofluorescence staining of autophagy proteins (Fig. 6B and $\mathrm{C}$ ). A strong reduction in the expression of LC3 (Fig. 6B) and the parallel accumulation of undegraded p62 (Fig. 6C) were observed. These data were corroborated by the western blotting of LC3 that revealed a strong reduction in the generation of LC3-II in the cells exposed to $\mathrm{NH}_{2}$-PS-NPs (Fig. 6D). We then checked whether the signaling pathways governing autophagy in OAW42 cells were inactivated by the $\mathrm{NH}_{2}$-PS-NPs. While the AKT-mTOR pathway was completely switched off (Fig. S5A, ESI $\dagger$ ), contrary to what was observed in OVCAR3 cells, the AMPK pathway was (partially) down-regulated (Fig. S5B, ESI $\dagger$ ).

\section{Pharmacological enhancement of autophagy attenuates $\mathrm{NH}_{2}$-PS-NP toxicity in OAW42 cells}

Given the findings above showing a pro-survival effect of autophagy, we reasoned that stimulating this process could protect OAW42 cells from $\mathrm{NH}_{2}$-PS-NP toxicity. Therefore, the cells were pre-treated with rapamycin or metformin and then exposed to the NPs. These treatments effectively enhanced autophagy as demonstrated by the increased immunostaining of LC3 and ATG4 and concomitant reduced accumulation of p62 in OAW42 cells (Fig. 7A and B). As shown in the images in Fig. 7C, in the rapamycin- or metformin-treated cultures, $\mathrm{NH}_{2}$-PS-NPs-induced necrosis was greatly prevented.

\section{6. $\mathrm{NH}_{2}-\mathrm{PS}-\mathrm{NP}$ toxicity in OAW42 cells is associated with mitochondrial anion-superoxide inactivation of ATG4}

Finally, we investigated the possible mechanism underlying the inhibition of autophagosome formation by $\mathrm{NH}_{2}$-PS-NPs. We focused on ATG4 that is among the principal effectors in the generation of LC3-II. ${ }^{44}$ The western blotting analysis showed that the cellular expression of ATG4 was greatly decreased upon prolonged exposure to the NPs (Fig. 8A). Since ATG4 is a redox-sensitive cysteine-protease, we wondered whether its inactivation, and possibly de-stabilization, was associated with the abnormal production of pro-oxidant species. Based on literature data and on our previous experience, ${ }^{45,46}$ we focused on the generation of anion superoxide at the mitochondrial level. The images in Fig. 8B indeed show that $\mathrm{NH}_{2}$-PS-NPs greatly triggered the production of mitochondrial anion superoxide.

\section{Preventing the production of mitochondrial anion- superoxide rescues ATG4-dependent autophagy and saves OAW42 cells from $\mathrm{NH}_{2}$-PS-NP toxicity}

In a separate study, we found that the polyphenol resveratrol (RV; 3,4,5-trihydroxylstibene) could restore ATG4 function 
A

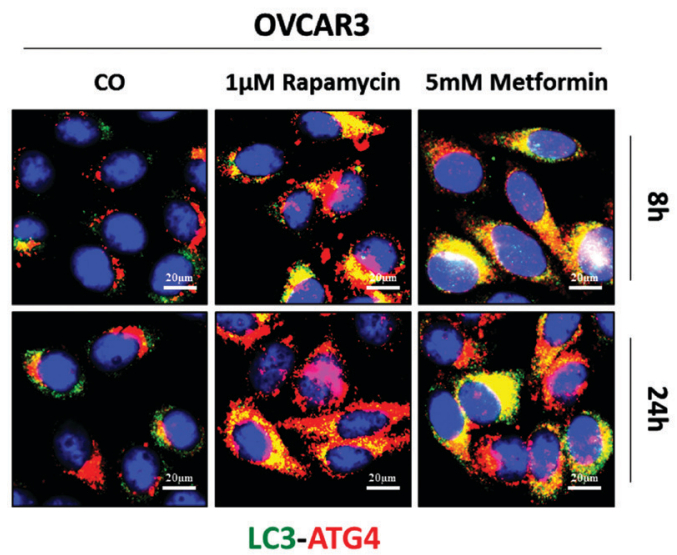

B

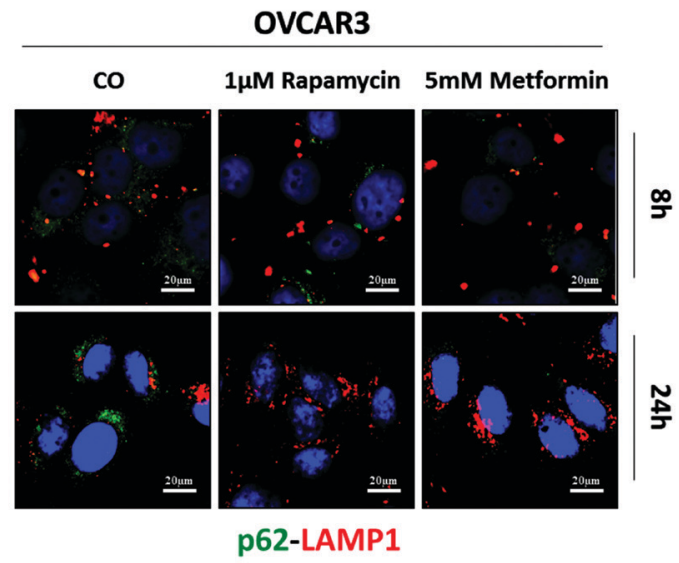

C

OVCAR3

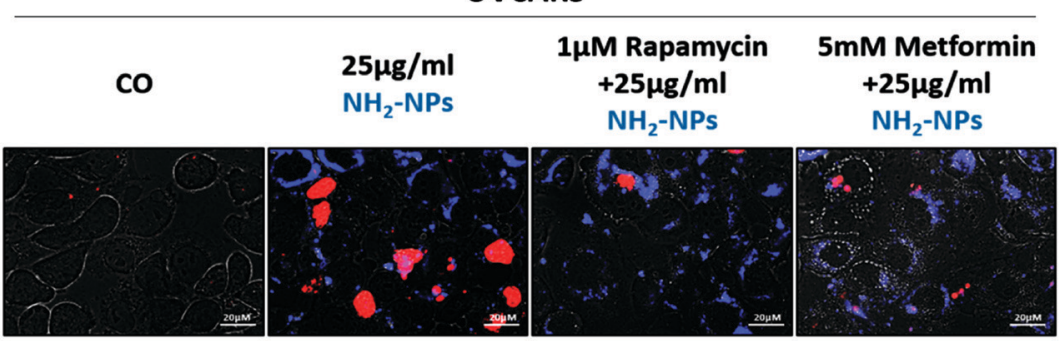

PI staining

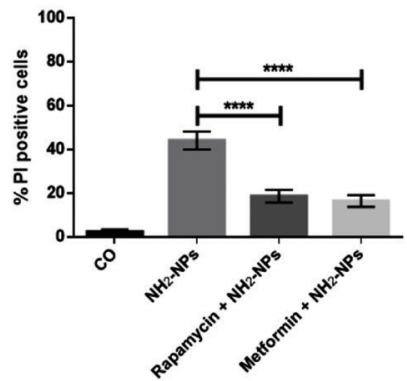

Fig. 5 Over-stimulation of autophagy protects OVCAR3 cells from $\mathrm{NH}_{2}$-PS-NP toxicity. (A and B) OVCAR3 cells adhered on coverslips were incubated with $1 \mu \mathrm{M}$ rapamycin or $5 \mathrm{mM}$ metformin for 8 and 24 hours. CO indicates control (untreated) cultures. Two different immunofluorescence double staining methods were performed: LC3 (green) - ATG4 (red) and p62 (green) - LAMP1 (red), shown in panel A and B, respectively. (C) OVCAR3 cells were pre-treated with $1 \mu \mathrm{M}$ rapamycin or $5 \mathrm{mM}$ metformin for 8 hours followed by the incubation with $25 \mu \mathrm{g} \mathrm{ml} \mathrm{l}^{-1} \mathrm{NH}_{2}-\mathrm{NPs}$ for 16 hours. CO indicates control (untreated) cultures. At the end of the incubation, cells were stained with propidium iodide (PI). Cell toxicity was quantified by counting the percentage of PI positive cells. Representative data from three independent experiments are shown in the histogram (\% \pm SD). On average, a minimum of $100-150$ cells were counted in randomly chosen fields by two independent investigators. Significance was considered as follows: ${ }^{* \star *} p<0.0001$. 
A
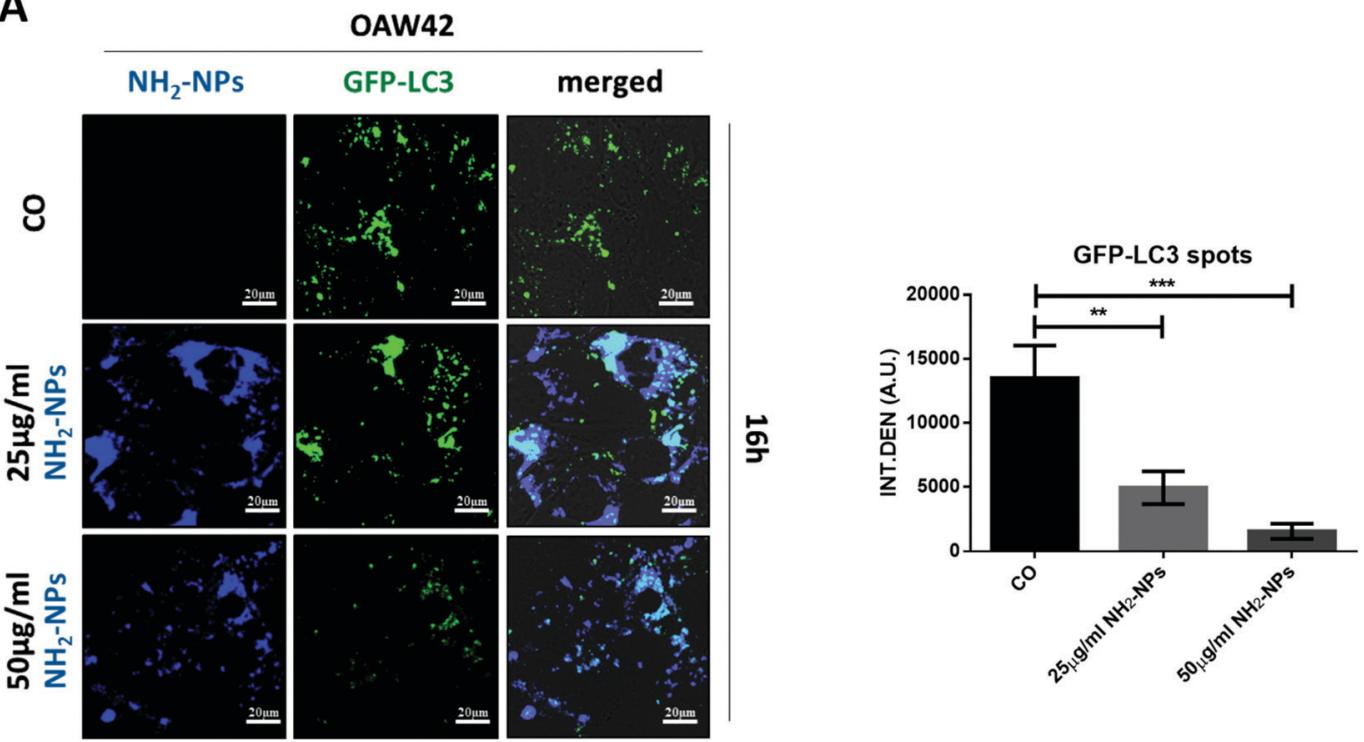

B

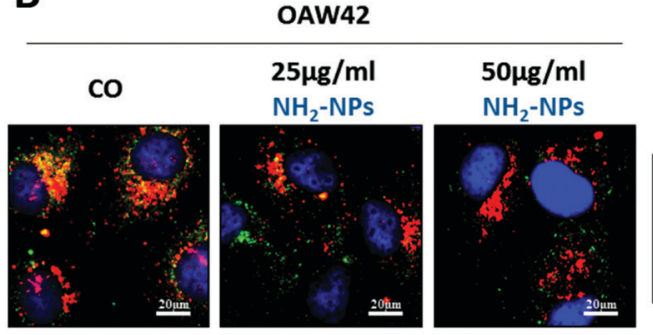

LC3-ATG4

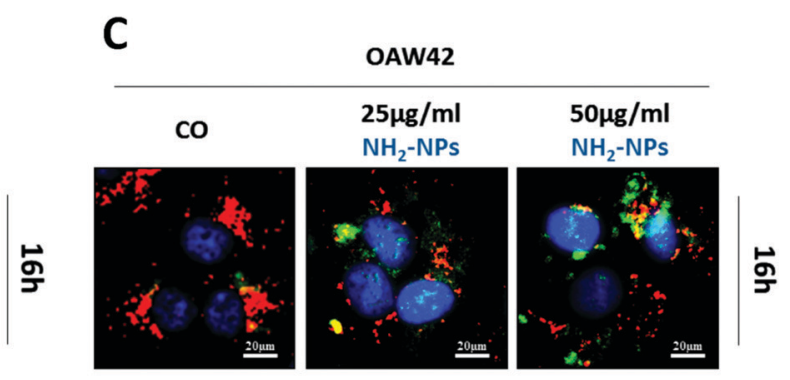

p62-LAMP1

D
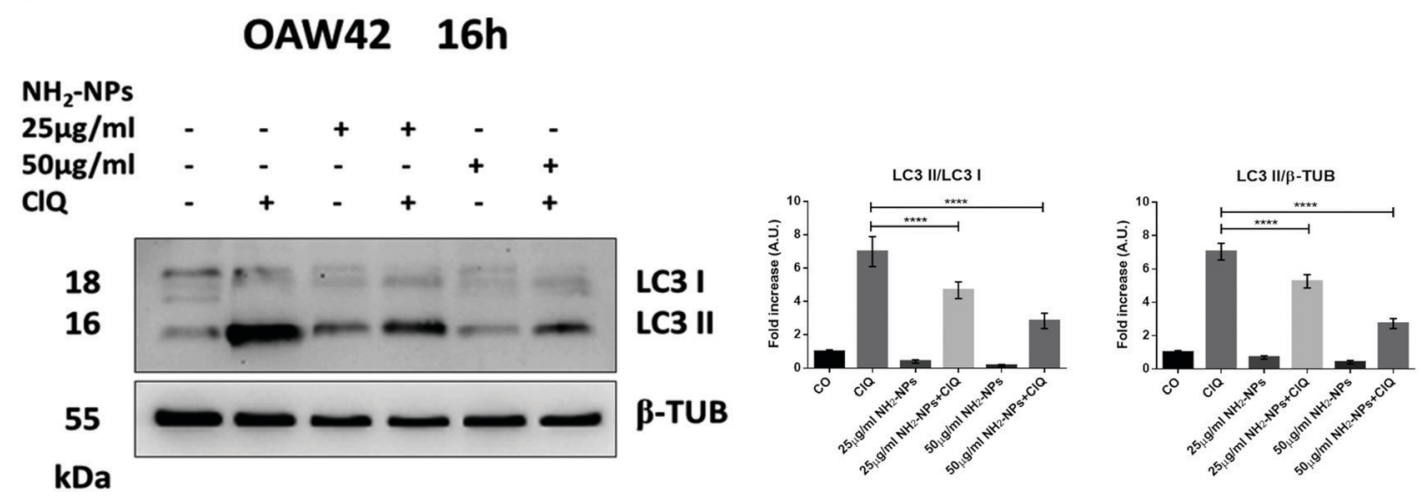

Fig. $6 \mathrm{NH}_{2}$-PS-NP toxicity in OAW42 cells associated with decreased autophagy. (A) OAW42 cells transfected with the GFP-LC3 plasmid were incubated with $25 \mathrm{~g} \mathrm{~m} \mathrm{ml}^{-1}$ or $50 \mu \mathrm{g} \mathrm{ml}^{-1} \mathrm{NH}_{2}$-NPs for 16 hours. CO indicates control (untreated) cultures. Autophagy modulation was estimated by counting GFP-LC3 spots in at least 100 cells in randomly chosen fields using ImageJ software. Data representing three independent experiments are reported in the histogram (A.U. \pm SD).

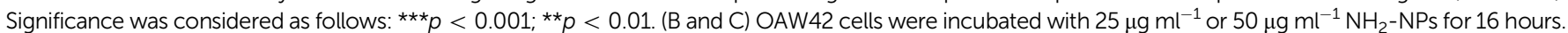
CO indicates control (untreated) cultures. Cells were immunofluorescence double stained: LC3 (green) - ATG4 (red) and p62 (green) - LAMP1 (red), respectively shown in panels B and C. (D) OAW42 cells were exposed to $25 \mu \mathrm{g} \mathrm{ml}^{-1}$ or $50 \mu \mathrm{g} \mathrm{ml}^{-1} \mathrm{NH}_{2}-\mathrm{NPs}$ in the presence/absence of chloroquine (ClQ) for 16 hours. The autophagy flux was monitored by the maturation of LC3-I to LC3-II by Western Blotting analysis. Densitometric analysis of LC3 of three independent experiments is included. Data are presented as an average (in A.U., arbitrary units) \pm SD. Significance was considered as follows: ${ }^{* \star \star} p<0.0001$.

and protective autophagy in neuronal-like cells subjected to oxidative stress. ${ }^{47}$ Here, we found that when the cells were exposed to the NPs in the presence of RV, the production of anion superoxide was greatly attenuated (Fig. 9A), necrotic cell death was largely prevented (Fig. 9B) and ATG4-dependent autophagy was strongly induced (Fig. 9C). 
A

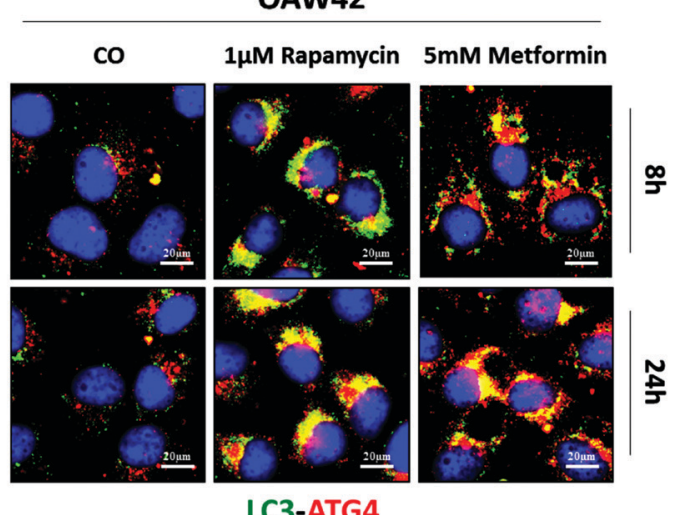

B

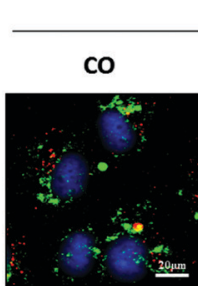

\section{OAW42}

$1 \mu \mathrm{M}$ Rapamycin $5 \mathrm{mM}$ Metformin
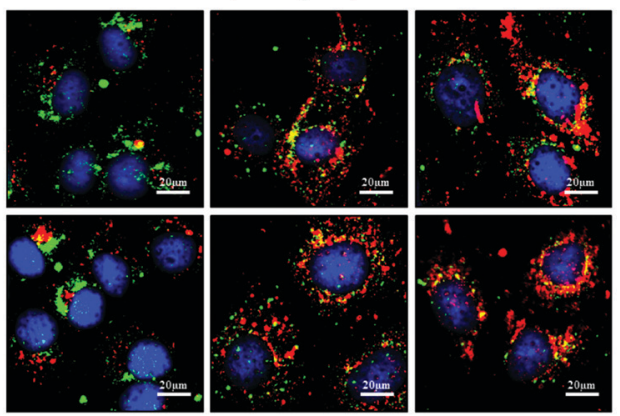

p62-LAMP1 $\stackrel{\infty}{=}$

$\stackrel{\infty}{=}$

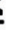

旁

C

OAW42

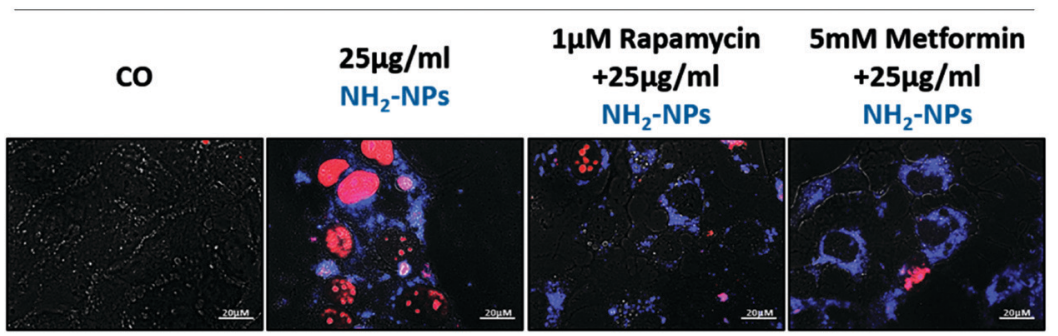

PI staining

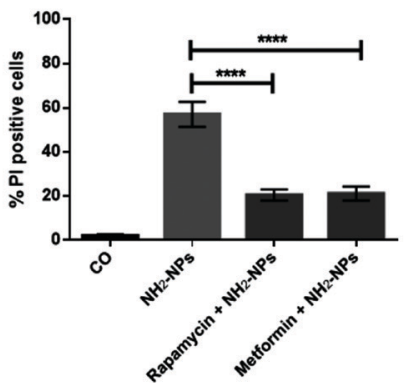

Fig. 7 Over-stimulation of autophagy protects OAW42 cells from $\mathrm{NH}_{2}$-PS-NP toxicity. (A and B) OAW42 cells were treated with $1 \mu \mathrm{M}$ rapamycin or $5 \mathrm{mM}$ metformin for 8 and 24 hours. CO indicates control (untreated) cultures. Cells were stained for immunofluorescence labeling of LC3 (green) ATG4 (red) or p62 (green) - LAMP1 (red), as indicated in panels A and B, respectively. (C) OAW42 cells were pre-treated with $1 \mu$ M rapamycin or 5 mM metformin for 8 hours followed by the incubation with $25 \mu \mathrm{g} \mathrm{ml}^{-1} \mathrm{NH}_{2}-\mathrm{NPs}$ for 16 hours. CO indicates control (untreated) cultures. To analyze cell death, the cells were stained with propidium iodide (PI) and immediately imaged using the fluorescence microscope. The amount of PI positive cells is shown in the histogram $(\% \pm S D)$. On average, a minimum of 100-150 cells were counted in randomly chosen fields by two independent investigators. Representative data shown are obtained from three independent replicates. Significance was considered as follows: ${ }^{\star \star \star \star} p<0.0001$. 
A

OAW42 16h
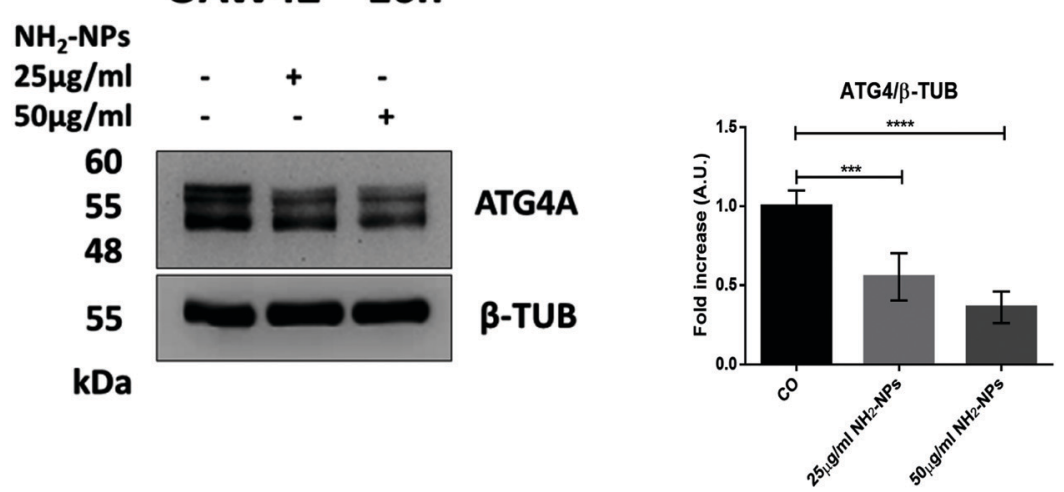

B
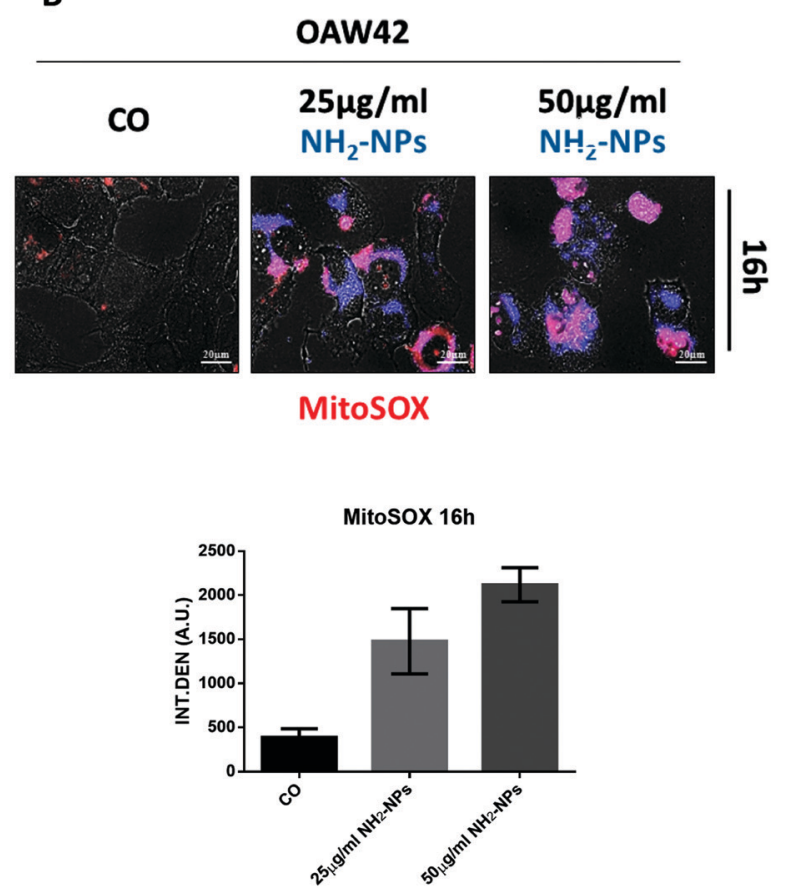

Fig. 8 Inhibition of autophagy caused by $\mathrm{NH}_{2}$-PS-NPs in OAW42 cells associated with ATG4 degradation and mitochondrial anion superoxide production. (A) OAW42 cells were treated with $25 \mu \mathrm{g} \mathrm{ml} l^{-1}$ or $50 \mu \mathrm{g} \mathrm{ml}^{-1} \mathrm{NH}_{2}$-NPs for 16 hours. Cell homogenates were analyzed by Western Blotting for ATG4 expression. Densitometric analysis was performed using the QuantityOne software. Data are presented in the histograms as an average (in A.U., Arbitrary Units) \pm SD. Significance was considered as follows: ${ }^{* * \star *} p<0.0001$; ${ }^{* \star *} p<0.001$. (B) OAW42 cells adhered on coverslips were exposed to $25 \mu \mathrm{g} \mathrm{ml}^{-1}$ or $50 \mu \mathrm{g} \mathrm{ml}^{-1} \mathrm{NH}_{2}$-NPs for 16 hours. CO indicates control (untreated) cultures. At the end, cells were stained with MitoSOX, which reveals the presence of mitochondrial anion superoxide. Representative images shown from three separated experiments were taken using the fluorescence microscope. The quantification of fluorescence intensity (INT.DEN. average \pm SD) was performed using the ImageJ software.

\section{Discussion}

Despite the efforts made for an early diagnosis, ovarian cancer is still diagnosed too late, when it is already spread in the peritoneum and distant sites. ${ }^{48}$ Once diagnosed, the therapeutic options include surgery, if the tumor is still operable, and chemotherapy. ${ }^{49}$ However, ovarian cancers soon develop chemo-resistance and relapse, which makes this malignant tumor the fifth most common cause of cancer deaths in women worldwide. ${ }^{50}$ Nanomedicine can be promising in the management of ovarian cancer. ${ }^{51}$ Fluorescent nanoprobes for the early diagnosis and image-guided surgery of ovarian cancer may improve prognosis through a more refined staging and cytoreductive debulking. ${ }^{8,43,52}$ Furthermore, NPs encapsulating a chemotherapy drug or siRNA targeting anti-apoptotic protein represent new weapons that can overcome the drug resistance in ovarian cancer. ${ }^{53-56}$ When designing nanotheranostics for cancer, a great effort is made to choose the most biocompatible material. However, it is intuitive that, besides the nanomaterial used, the genetic, epigenetic and metabolic status of the cell influences the response to the NP. Most of the publications in nanomedicine focus on the intrinsic properties of the NP, while paying less attention to the contribution of the intrinsic cell properties in the cellular response. The present work aimed at filling, though partially, this gap of knowledge. 
A

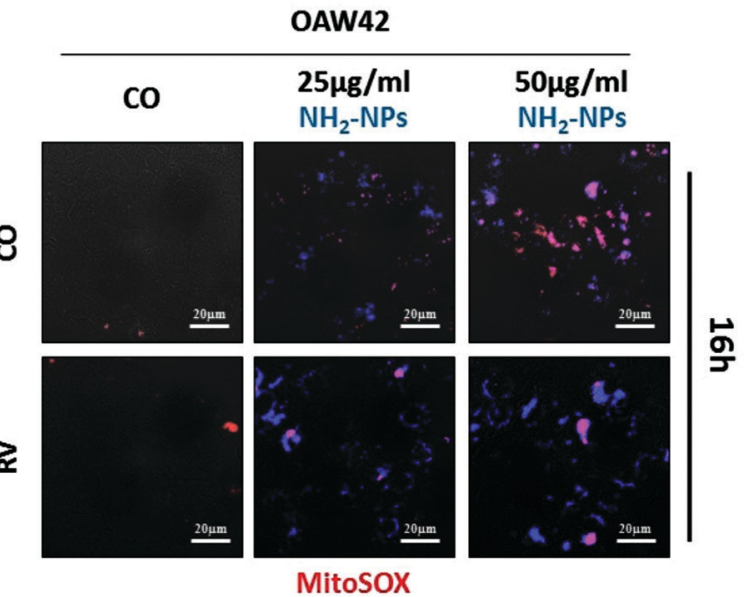

B

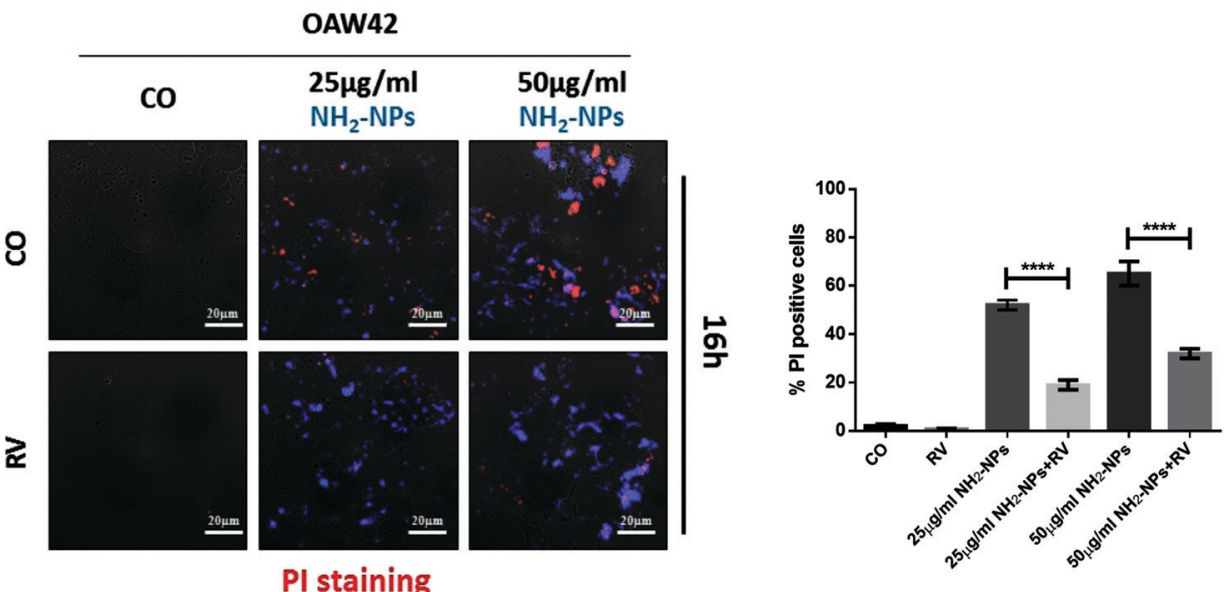

C

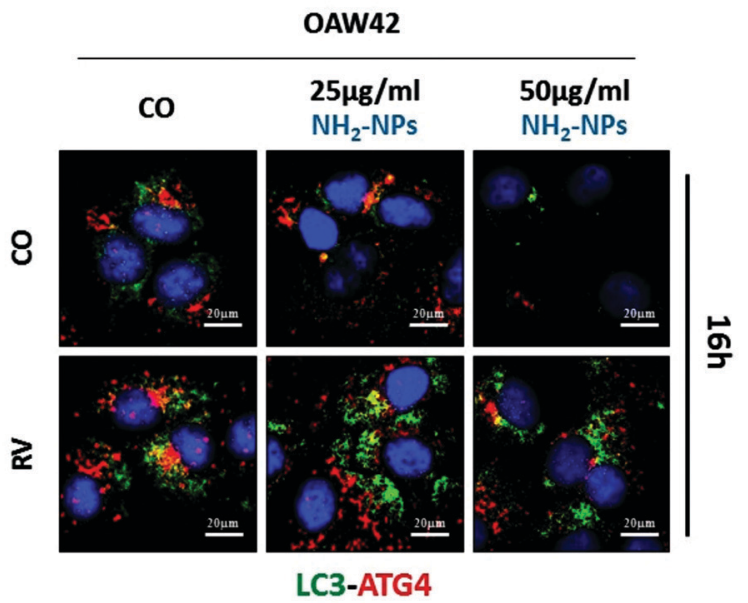

Fig. 9 Inhibition of mitochondrial ROS production by resveratrol restores ATG4-mediated autophagy and prevents cell death in OAW42 cells exposed to $\mathrm{NH}_{2}$-PS-NPs. OAW42 cells adhered on coverslips were exposed to $25 \mu \mathrm{g} \mathrm{ml} \mathrm{l}^{-1}$ or $50 \mu \mathrm{g} \mathrm{ml}^{-1} \mathrm{NH}_{2}$-NPs for 16 hours in the absence or presence of resveratrol (RV). CO indicates control (untreated) cultures. At the end, cells were stained with MitoSOX (panel A), or with Propidium lodide (PI, panel B; quantification of necrotic cells is included), or fixed and immunofluorescence stained for LC3 and ATG4 (panel C). Representative images shown from three separated experiments were taken using the fluorescence microscope.

Here, we used NPs made of polystyrene. This material has been used for the development of nanotheranostics. ${ }^{57,58}$ In addition, the availability of charged PS-NPs embedded with a fluorescent probe makes these NPs a valid tool for monitoring the uptake and toxicity at the cellular level. ${ }^{15-17,59-61}$ Thus, PS-NPs can be used as a paradigm for in vitro investigation of 
the mechanisms of toxicity. In agreement with our previous observations, ${ }^{17}$ we found that $\mathrm{NH}_{2}$-PS-NPs (50 $\mathrm{nm}$ in diameter) were toxic, whereas COOH-functionalized PS-NPs $(30 \mathrm{~nm}$ in diameter) were not, to ovarian cancer cells. Though a direct comparison cannot be made because of the slight difference in the diameter of the PS-NPs used here, it seems that (in our experimental model) the surface charge, not the material, mainly affects the cell fate. Consistently, $\mathrm{NH}_{2}$-PS, not COOH-PS, NPs were shown to be cytotoxic in other cell types. ${ }^{60,62,63}$ For instance, both $\mathrm{COOH}$ - and $\mathrm{NH}_{2}$-PS-NPs of $50 \mathrm{~nm}$ were able to induce autophagy in HeLa cells, though the former were not toxic when administered at $50 \mu \mathrm{g} \mathrm{ml}^{-1}$ for $24 \mathrm{~h}$ while the latter were toxic when administered at as low as $10 \mu \mathrm{g} \mathrm{ml}^{-1}$ for $24 \mathrm{~h}^{63}$ In our study, $\mathrm{NH}_{2}$-PS-NPs (50 $\mathrm{nm}$ diameter) caused extensive necrosis when administered at $50 \mu \mathrm{g} \mathrm{m}{ }^{-1}$ for $16 \mathrm{~h}$ both in OAW42 and OVCAR3 cells. Though both cell lines could trigger BAX-dependent apoptosis in response to the chemotherapeutic drug oxaliplatin, this pathway was not activated by $\mathrm{NH}_{2}$-PS-NPs. On dissecting the mechanisms of toxicity, we found that the cellular stress response to $\mathrm{NH}_{2}$-PS-NPs manifested as autophagy was different in OVCAR3 and OAW42 cells, being induced in the former and inhibited in the latter. With respect to the two major pathways controlling autophagy and cell survival under stress, i.e. the AKT-mTOR and AMPK pathways, it was found that in both cell lines, $\mathrm{NH}_{2}$-PS-NPs totally switched off the AKT-mTOR pathway, consistent with the induction of autophagy as a stress response and with a previous report. ${ }^{23}$ Yet, the AMPK pathway was strongly induced in the OVCAR3 cells (thus reinforcing the induction of autophagy) while it was (partially) down-regulated in OAW42. Several reports have shown that autophagy and cell death are triggered on treatments with a variety of nanomaterials (reviewed in ref. 29 and 30). Induction of autophagy and cell death by PS-NPs has been reported in other cell models. ${ }^{64}$ Segatori and co-workers have shown that induction of autophagy by PS-NPs is associated with the nuclear translocation of TFEB, a transcription factor for several autophagy genes. ${ }^{62}$ These authors also found that COOH-PS-NPs stimulated autophagy degradation, while $\mathrm{NH}_{2}$-PS-NPs caused lysosomal dysfunction and eventually impaired the autophagy flux. ${ }^{62}$

To our knowledge, this is the first report showing that, at least in some cell types, NPs can instead inhibit autophagy at the very early step of autophagosome formation.

Autophagy is per se a pro-survival pathway, aimed at removing damaged and potentially harmful proteins and organelles, as well as at preventing ROS generation and DNA and protein damages. ${ }^{32}$ There is a complex cross-talk between autophagy, apoptosis and necroptosis, in which autophagy may prevent or facilitate cell death depending on the type and intensity of the stimulus as well as the genetic/epigenetic/metabolic status of the target cells. ${ }^{65}$ In this cross-talk, a critical role is played by ROS, which might affect the autophagy machinery. ${ }^{45,66}$ Here, we found that $\mathrm{NH}_{2}$-PS-NPs were toxic to OVCAR3 despite the induction of autophagy. We could demonstrate that autophagy was indeed protective, yet insufficient. In fact, when induction of autophagy was prevented by BECN1 or $A T G 7$ gene silencing, the toxicity induced by $\mathrm{NH}_{2}$-PS-NPs was greatly enhanced.
Conversely, the hyper-stimulation of autophagy with rapamycin or metformin largely protected OVCAR3 from $\mathrm{NH}_{2}$-PS-NP toxicity. In contract, $\mathrm{NH}_{2}$-PS-NPs inhibited autophagy in OAW42 cells, and this was the reason for the occurrence of necrosis. In fact, here again, rapamycin and metformin elicited protection from $\mathrm{NH}_{2}$-PSNP toxicity. It was found that these NPs inhibited the generation of the lipidated LC3-II isoform needed for autophagosome formation, and this was associated with a reduced expression of ATG4, the enzyme responsible for processing LC3. ${ }^{33}$ Searching for a mechanistic explanation, we focused on the mitochondrial production of ROS that could account for ATG4 dysfunction based on our previous studies. ${ }^{46,66}$ We found that $\mathrm{NH}_{2}$-PS-NPs greatly triggered the production of mitochondrial anion superoxide in OAW42 cells. To demonstrate that indeed this is the mechanism through which ATG4 is inactivated, we used RV, an inhibitor of mitochondrial anion superoxide production that was previously shown to rescue ATG4-mediated protective autophagy. ${ }^{47} \mathrm{RV}$ was shown to be able to scavenge hydroxyl $\left({ }^{\circ} \mathrm{OH}\right)$ and anion superoxide $\left(\mathrm{O}_{2}{ }^{\bullet-}\right),{ }^{67}$ to inhibit $\mathrm{NAD}(\mathrm{P}) \mathrm{H}$ :quinone oxidoreductase 2 (NQO2; also called QR2), ${ }^{68}$ and to induce autophagy by activating the AMPK pathway. ${ }^{69}$ The data showed that in fact RV could protect OAW42 cells from $\mathrm{NH}_{2}$-PS-NPs by inhibiting the production of mitochondrial anion superoxide and thus restoring the ability to form ATG4-mediated LC3-positive autophagosomes.

\section{Conclusions}

Nanomedicine has the ambition to allow the diagnosis and therapy of diseases using NPs complexed with reporter molecules and drugs. The medical use of NPs bears the risk of side effects caused by unwanted cytotoxicity associated with the physical-chemical characteristics of the NPs, especially the material, the size and the presence of the charged group on the surface. Also, the intrinsic characteristics of the target cell will determine the type and consequences of the stress response elicited by the NPs.

The present data provide a proof of principle that $\mathrm{NH}_{2}$ functionalized PS-NPs elicit a differential response in terms of autophagy regulation in cancer cells having a different genetic background. Intriguingly, toxicity from $\mathrm{NH}_{2}$-PS-NPs was the consequence of insufficient induction of protective autophagy in one cell type, and of impairment of autophagosome formation in another cell type. These findings point to the necessity of a better assessment of the genetic/epigenetic and metabolic status of the target cells when designing theranostics for cancer therapy, in complete agreement with the principle of personalized medicine. We propose that such assessment should include the genes and pathways impinging on the autophagy process.

\section{Abbreviations}

$\begin{array}{ll}\text { ATG } & \text { Autophagy-related } \\ \text { GFP } & \text { Green fluorescent protein } \\ \text { NP } & \text { Nanoparticle } \\ \text { PS } & \text { Polystyrene } \\ \text { ROS } & \text { Reactive oxygen species }\end{array}$




\section{Author contributions}

Christian Seca and Alessandra Ferraresi: designed methods and experiments, performed the experiments of endocytosis and toxicity, acquired and interpreted the imaging data, and wrote the first draft of the paper; Suratchanee Phadngam and Chiara Vidoni: performed the experiments of gene silencing, performed the imaging quantification and the statistical analysis, and wrote the ESI; $\dagger$ Ciro Isidoro: defined the research theme, supervised the experimental work, interpreted the results, and revised the paper. All authors read and approved the final version of the paper and agreed to be accountable for all aspects of the work.

\section{Conflicts of interest}

To the best of our knowledge, the named authors have no conflict of interest, financial or otherwise.

\section{Acknowledgements}

C. S. and S. P. were supported with a fellowship funded by the Compagnia S. Paolo (Therasil CSP 2014 project) and by Associazione per la Ricerca Medica Ippocrate-Rhazi (ARM-IR, Novara, Italy), respectively. The Microscope fluorescence imaging facility was donated by Comoli, Ferrari \& SpA (Novara, Italy). Dr Fabio Carniato (Università del Piemonte Orientale, Dipartimento di Scienze e Innovazione Tecnologica, Alessandria, Italy) and Mr Nilesh Kumar Dhakar (Dipartimento di Chimica, Università di Torino, Torino, Italy) have performed the $\mathrm{Z}$ potential measurements.

\section{References}

1 J. C. Park, M. K. Yu, G. I. An, S. I. Park, J. Oh, H. J. Kim, J. H. Kim, E. K. Wang, I. H. Hong, Y. S. Ha, T. H. Choi, K. S. Jeong, Y. Chang, M. J. Welch, S. Jon and J. Yoo, Facile preparation of a hybrid nanoprobe for triple-modality optical/PET/MR imaging, Small, 2010, 6(24), 2863-2868, DOI: $10.1002 / \mathrm{smll} .201001418$.

2 F. Carniato, L. Tei, S. Phadngam, C. Isidoro and M. Botta, NaGdF4 Nanoparticles Coated with Functionalised Ethylenediaminetetraacetic Acid as Versatile Probes for Dual Optical and Magnetic Resonance Imaging, ChemPlusChem, 2015, 80, 503-510, DOI: 10.1002/cplu.201402245.

3 S. Biffi, R. Voltan, E. Rampazzo, L. Prodi, G. Zauli and P. Secchiero, Applications of nanoparticles in cancer medicine and beyond: optical and multimodal in vivo imaging, tissue targeting and drug delivery, Expert Opin. Drug Delivery, 2015, 12(12), 1837-1849, DOI: 10.1517/17425247.2015.1071791.

4 S. Biffi, L. Petrizza, C. Garrovo, E. Rampazzo, L. Andolfi, P. Giustetto, I. Nikolov, G. Kurdi, M. B. Danailov, G. Zauli, P. Secchiero and L. Prodi, Multimodal near-infrared-emitting PluS Silica nanoparticles with fluorescent, photoacoustic, and photothermal capabilities, Int. J. Nanomed., 2016, 11, 4865-4874.

5 G. M. Nabar, K. D. Mahajan, M. A. Calhoun, A. D. Duong, M. S. Souva, J. Xu, C. Czeisler, V. K. Puduvalli, J. J. Otero, B. E. Wyslouzil and J. O. Winter, Micelle-templated, poly(lactic-co-glycolic acid) nanoparticles for hydrophobic drug delivery, Int. J. Nanomed., 2018, 13, 351-366, DOI: 10.2147/IJN.S142079.

6 C. Andreou, S. Pal, L. Rotter, J. Yang and M. F. Kircher, Molecular Imaging in Nanotechnology and Theranostics, Mol. Imaging Biol., 2017, 19(3), 363-372, DOI: 10.1007/s11307-017-1056-z.

7 Y. Xin, T. Liu and C. Yang, Development of PLGA-lipid nanoparticles with covalently conjugated indocyanine green as a versatile nanoplatform for tumor-targeted imaging and drug delivery, Int. J. Nanomed., 2016, 11, 5807-5821.

8 Y. Meng, Z. Zhang, K. Liu, L. Ye, Y. Liang and W. Gu, Aminopeptidase N (CD13) targeted MR and NIRF dual-modal imaging of ovarian tumor xenograft, Mater. Sci. Eng., C, 2018, 93, 968-974, DOI: 10.1016/j.msec.2018.09.002.

9 F. Carniato, D. Alberti, A. Lapadula, J. Martinelli, C. Isidoro, S. Geninatti Crich and L. Tei, Multifunctional Gd-based mesoporous silica nanotheranostic for anticancer drug delivery, J. Mater. Chem. B, 2019, 7, 3143-3152, DOI: 10.1039/ C9TB00375D.

10 Y. Zhao, N. L. Fletcher, T. Liu, A. C. Gemmell, Z. H. Houston, I. Blakey and K. J. Thurecht, In vivo therapeutic evaluation of polymeric nanomedicines: effect of different targeting peptides on therapeutic efficacy against breast cancer, Nanotheranostics, 2018, 2(4), 360-370, DOI: 10.7150/ntno.27142.

11 F. Chen, K. Ma, B. Madajewski, L. Zhuang, L. Zhang, K. Rickert, M. Marelli, B. Yoo, M. Z. Turker, M. Overholtzer, T. P. Quinn, M. Gonen, P. Zanzonico, A. Tuesca, M. A. Bowen, L. Norton, J. A. Subramony, U. Wiesner and M. S. Bradbury, Ultrasmall targeted nanoparticles with engineered antibody fragments for imaging detection of HER2-overexpressing breast cancer, Nat. Commun., 2018, 9(1), 4141, DOI: 10.1038/s41467-018-06271-5.

12 N. Oh and J. H. Park, Endocytosis and exocytosis of nanoparticles in mammalian cells, Int. J. Nanomed., 2014, 9(Suppl 1), 51-63, DOI: 10.2147/IJN.S26592.

13 J. Zhang, H. Tang, Z. Liu and B. Chen, Effects of major parameters of nanoparticles on their physical and chemical properties and recent application of nanodrug delivery system in targeted chemotherapy, Int. J. Nanomed., 2017, 12, 8483-8493, DOI: 10.2147/IJN.S148359.

14 X. Q. Liu and R. Z. Tang, Biological responses to nanomaterials: understanding nano-bio effects on cell behaviors, Drug Delivery, 2017, 24(sup1), 1-15, DOI: 10.1080/10717544.2017.1375577.

15 M. Ekkapongpisit, A. Giovia, G. Nicotra, M. Ozzano, G. Caputo and C. Isidoro, Labeling and exocytosis of secretory compartments in RBL mastocytes by polystyrene and mesoporous silica nanoparticles, Int. J. Nanomed., 2012, 7, 1829-1840, DOI: 10.2147/IJN.S29034.

16 I. Fiorentino, R. Gualtieri, V. Barbato, V. Mollo, S. Braun, A. Angrisani, M. Turano, M. Furia, P. A. Netti, D. Guarnieri, S. Fusco and R. Talevi, Energy independent uptake and release of polystyrene nanoparticles in primary mammalian cell cultures, Exp. Cell Res., 2015, 330(2), 240-247, DOI: 10.1016/j.yexcr.2014.09.017.

17 M. Ekkapongpisit, A. Giovia, C. Follo, G. Caputo and C. Isidoro, Biocompatibility, endocytosis, and intracellular trafficking of mesoporous silica and polystyrene nanoparticles in ovarian 
cancer cells: effects of size and surface charge groups, Int. J. Nanomed., 2012, 7, 4147-4158, DOI: 10.2147/IJN.S33803.

18 X. Jiang, J. Dausend, M. Hafner, A. Musyanovych, C. Röcker, K. Landfester, V. Mailänder and G. U. Nienhaus, Specific effects of surface amines on polystyrene nanoparticles in their interactions with mesenchymal stem cells, Biomacromolecules, 2010, 11(3), 748-753, DOI: 10.1021/bm901348z.

19 E. Gianotti, C. A. Bertolino, C. Benzi, G. Nicotra, G. Caputo, R. Castino, C. Isidoro and S. Coluccia, Photoactive hybrid nanomaterials: indocyanine immobilized in mesoporous MCM-41 for "in-cell" bioimaging, ACS Appl. Mater. Interfaces, 2009, 1(3), 678-687, DOI: 10.1021/am800196r.

20 J. J. Li, D. Hartono, C.-N. Ong, B.-H. Bay and L.-Y. L. Yung, Autophagy and oxidative stress associated with gold nanoparticles, Biomaterials, 2010, 31, 5996-6003.

21 B. Halamoda Kenzaoui, C. Chapuis Bernasconi, S. GuneyAyra and L. Juillerat-Jeanneret, Induction of oxidative stress, lysosome activation and autophagy by nanoparticles in human brain-derived endothelial cells, Biochem. J., 2012, 441, 813-821.

22 Y. Liu, W. Li, F. Lao, Y. Liu, L. Wang, R. Bai, Y. Zhao and C. Chen, Intracellular dynamics of cationic and anionic polystyrene nanoparticles without direct interaction with mitotic spindle and chromosomes, Biomaterials, 2011, 32(32), 8291-8303, DOI: 10.1016/j.biomaterials.2011.07.037.

23 C. Loos, T. Syrovets, A. Musyanovych, V. Mailänder, K. Landfester and T. Simmet, Amino-functionalized nanoparticles as inhibitors of mTOR and inducers of cell cycle arrest in leukemia cells, Biomaterials, 2014, 35, 1944-1953.

24 M. I. Khan, A. Mohammad, G. Patil, S. A. Naqvi, L. K. Chauhan and I. Ahmad, Induction of ROS, mitochondrial damage and autophagy in lung epithelial cancer cells by iron oxide nanoparticles, Biomaterials, 2012, 33(5), 1477-1488, DOI: 10.1016/ j.biomaterials.2011.10.080.

25 E. Panzarini, V. Inguscio, B. A. Tenuzzo, E. Carata and L. Dini, Nanomaterials and autophagy: new insights in cancer treatment, Cancer, 2013, 5(1), 296-319, DOI: 10.3390/cancers5010296.

26 F. Wei, Y. Wang, Z. Luo, Y. Li and Y. Duan, New findings of silica nanoparticles induced ER autophagy in human colon cancer cell, Sci. Rep., 2017, 7, 42591, DOI: 10.1038/srep42591.

27 X. Ma, Y. Wu, S. Jin, Y. Tian, X. Zhang, Y. Zhao, L. Yu and $\mathrm{X}$. J. Liang, Gold nanoparticles induce autophagosome accumulation through size-dependent nanoparticle uptake and lysosome impairment, ACS Nano, 2011, 5(11), 8629-8639, DOI: $10.1021 / \mathrm{nn} 202155 \mathrm{y}$.

28 R. Krętowski, M. Kusaczuk, M. Naumowicz, J. Kotyńska, B. Szynaka and M. Cechowska-Pasko, The Effects of Silica Nanoparticles on Apoptosis and Autophagy of Glioblastoma Cell Lines, Nanomaterials, 2017, 7(8), 230, DOI: 10.3390/nano7080230.

29 R. Mohammadinejad, M. A. Moosavi, S. Tavakol, D. Ö. Vardar, A. Hosseini, M. Rahmati, L. Dini, S. Hussain, A. Mandegary and D. J. Klionsky, Necrotic, apoptotic and autophagic cell fates triggered by nanoparticles, Autophagy, 2018, 1-30, DOI: 10.1080/15548627.2018.1509171.

30 Y. Li and D. Ju, The Role of Autophagy in NanoparticlesInduced Toxicity and Its Related Cellular and Molecular
Mechanisms, Adv. Exp. Med. Biol., 2018, 1048, 71-84, DOI: 10.1007/978-3-319-72041-8_5.

31 Y. Feng, D. He, Z. Yao and D. J. Klionsky, The machinery of macroautophagy, Cell Res., 2014, 24(1), 24-41, DOI: 10.1038/ cr.2013.168.

32 G. Kroemer, G. Mariño and B. Levine, Autophagy and the integrated stress response, Mol. Cell, 2010, 40(2), 280-293, DOI: 10.1016/j.molcel.2010.09.023.

33 Z. Metlagel, C. Otomo, K. Ohashi, G. Takaesu and T. Otomo, Structural insights into E2-E3 interaction for LC3 lipidation, Autophagy, 2014, 10(3), 522-523, DOI: 10.4161/auto.27594.

34 M. Lippai and P. Lőw, The role of the selective adaptor p62 and ubiquitin-like proteins in autophagy, BioMed Res. Int., 2014, 2014, 832704, DOI: 10.1155/2014/832704.

35 M. Marinković, M. Šprung, M. Buljubašić and I. Novak, Autophagy Modulation in Cancer: Current Knowledge on Action and Therapy, Oxid. Med. Cell. Longevity, 2018, 2018, 8023821, DOI: 10.1155/2018/8023821.

36 C. Peracchio, O. Alabiso, G. Valente and C. Isidoro, Involvement of autophagy in ovarian cancer: a working hypothesis, J. Ovarian Res., 2012, 5(1), 22, DOI: 10.1186/1757-2215-5-22.

37 C. Thuwajit, A. Ferraresi, R. Titone, P. Thuwajit and C. Isidoro, The metabolic cross-talk between epithelial cancer cells and stromal fibroblasts in ovarian cancer progression: Autophagy plays a role, Med. Res. Rev., 2018, 38(4), 1235-1254, DOI: 10.1002/med.21473.

38 S. Thongchot, C. Vidoni, A. Ferraresi, W. Loilome, P. Yongvanit, N. Namwat and C. Isidoro, Dihydroartemisinin induces apoptosis and autophagy-dependent cell death in cholangiocarcinoma through a DAPK1-BECLIN1 pathway, Mol. Carcinog., 2018, 57(12), 1735-1750, DOI: 10.1002/mc.22893.

39 N. F. Trincheri, C. Follo, G. Nicotra, C. Peracchio, R. Castino and C. Isidoro, Resveratrol-induced apoptosis depends on the lipid kinase activity of Vps34 and on the formation of autophagolysosomes, Carcinogenesis, 2008, 29(2), 381-389.

40 R. Castino, C. Peracchio, A. Salini, G. Nicotra, N. F. Trincheri, M. Démoz, G. Valente and C. Isidoro, Chemotherapy drug response in ovarian cancer cells strictly depends on a cathepsin D-Bax activation loop, J. Cell. Mol. Med., 2009, 13(6), 1096-1109, DOI: 10.1111/j.1582-4934.2008.00435.x.

41 D. J. Klionsky, et al., Guidelines for the use and interpretation of assays for monitoring autophagy (3rd edn), Autophagy, 2016, 12(1), 1-222, DOI: 10.1080/15548627.2015.1100356.

42 M. Paquette, L. El-Houjeiri and A. Pause, mTOR Pathways in Cancer and Autophagy, Cancers, 2018, 10(1), 18, DOI: 10.3390/cancers10010018.

43 Y. Wang, W. Xu, Z. Yan, W. Zhao, J. Mi, J. Li and H. Yan, Metformin induces autophagy and G0/G1 phase cell cycle arrest in myeloma by targeting the AMPK/mTORC1 and mTORC2 pathways, J. Exp. Clin. Cancer Res., 2018, 37(1), 63, DOI: 10.1186/s13046-018-0731-5.

44 K. J. Kauffman, S. Yu, J. Jin, B. Mugo, N. Nguyen, A. O’Brien, S. Nag, A. H. Lystad and T. J. Melia, Delipidation of mammalian Atg8-family proteins by each of the four ATG4 proteases, Autophagy, 2018, 14(6), 992-1010, DOI: 10.1080/ 15548627.2018.1437341. 
45 R. Scherz-Shouval, E. Shvets, E. Fass, H. Shorer, L. Gil and Z. Elazar, Reactive oxygen species are essential for autophagy and specifically regulate the activity of Atg4, EMBO J., 2007, 26(7), 1749-1760.

46 C. Vidoni, A. Castiglioni, C. Seca, E. Secomandi, M. A. Melone and C. Isidoro, Dopamine exacerbates mutant Huntingtin toxicity via oxidative-mediated inhibition of autophagy in SH-SY5Y neuroblastoma cells: Beneficial effects of antioxidant therapeutics, Neurochem. Int., 2016, 101, 132-143, DOI: 10.1016/j.neuint.2016.11.003.

47 C. Vidoni, E. Secomandi, A. Castiglioni, M. A. B. Melone and C. Isidoro, Resveratrol protects neuronal-like cells expressing mutant Huntingtin from dopamine toxicity by rescuing ATG4-mediated autophagosome formation, Neurochem. Int., 2018, 117, 174-187, DOI: 10.1016/j.neuint.2017.05.013.

48 J. Prat, FIGO's staging classification for cancer of the ovary, fallopian tube, and peritoneum: Abridged republication, J. Gynecol. Oncol., 2015, 26, 87-89, DOI: 10.3802/jgo.2015.26.2.87.

49 R. L. Coleman, B. J. Monk, A. K. Sood and T. J. Herzog, Latest research and treatment of advanced-stage epithelial ovarian cancer, Nat. Rev. Clin. Oncol., 2013, 10(4), 211-224, DOI: $10.1038 /$ nrclinonc.2013.5.

50 R. L. Siegel, K. D. Miller and A. Jemal, Cancer statistics, 2017, Ca-Cancer J. Clin., 2017, 67, 7-30, DOI: 10.3322/caac.21387.

51 G. Di Lorenzo, G. Ricci, G. M. Severini, F. Romano and S. Biffi, Imaging and therapy of ovarian cancer: clinical application of nanoparticles and future perspectives, Theranostics, 2018, 8(16), 4279-4294, DOI: 10.7150/thno.26345.

52 T. Mangeolle, I. Yakavets, S. Marchal, M. Debayle, T. Pons, L. Bezdetnaya and F. Marchal, Fluorescent Nanoparticles for the Guided Surgery of Ovarian Peritoneal Carcinomatosis, Nanomaterials, 2018, 8(8), 572, DOI: 10.3390/nano8080572.

53 W. Zheng, M. Li, Y. Lin and X. Zhan, Encapsulation of verapamil and doxorubicin by MPEG-PLA to reverse drug resistance in ovarian cancer, Biomed. Pharmacother., 2018, 108, 565-573, DOI: 10.1016/j.biopha.2018.09.039.

54 S. Nam, S. Y. Lee, W. S. Kang and H. J. Cho, Development of Resveratrol-Loaded Herbal Extract-Based Nanocomposites and Their Application to the Therapy of Ovarian Cancer, Nanomaterials, 2018, 8(6), 384, DOI: 10.3390/nano8060384.

55 C. Risnayanti, Y. S. Jang, J. Lee and H. J. Ahn, PLGA nanoparticles co-delivering MDR1 and BCL2 siRNA for overcoming resistance of paclitaxel and cisplatin in recurrent or advanced ovarian cancer, Sci. Rep., 2018, 8(1), 7498, DOI: 10.1038/s41598-018-25930-7.

56 J. Wang, Y. Song, M. Zhang, Z. Wu, Y. J. Xu, J. Lin, D. Ling, Y. Sheng, Y. Lu and Q. Wu, A liposomal curcumol nanocomposite for magnetic resonance imaging and endoplasmic reticulum stress-mediated chemotherapy of human primary ovarian cancer, J. Mater. Chem. B, 2019, DOI: 10.1039/C8TB03123A.

57 M. Pellach, I. Grinberg and S. Margel, Near IR fluorescent polystyrene/albumin core/shell nanoparticles for specific targeting of colonic neoplasms, Macromol. Biosci., 2012, 12(11), 1472-1479, DOI: 10.1002/mabi.201200142.

58 F. Wang, G. M. Pauletti, J. Wang, J. Zhang, R. C. Ewing, Y. Wang and D. Shi, Dual surface-functionalized Janus nanocomposites of polystyrene $/ \mathrm{Fe}_{3} \mathrm{O}_{4} @ \mathrm{SiO}_{2}$ for simultaneous tumor cell targeting and stimulus-induced drug release, Adv. Mater., 2013, 25(25), 3485-3489, DOI: 10.1002/adma.201301376.

59 P. J. Smith, M. Giroud, H. L. Wiggins, F. Gower, J. A. Thorley, B. Stolpe, J. Mazzolini, R. J. Dyson and J. Z. Rappoport, Cellular entry of nanoparticles via serum sensitive clathrin-mediated endocytosis, and plasma membrane permeabilization, Int. J. Nanomed., 2012, 7, 2045-2055, DOI: 10.2147/IJN.S29334. Epub 2012 Apr 24. Erratum in: Int. J. Nanomed. 2015, 10, 3987.

60 T. Xia, M. Kovochich, J. Brant, M. Hotze, J. Sempf, T. Oberley, C. Sioutas, J. I. Yeh, M. R. Wiesner and A. E. Nel, Comparison of the abilities of ambient and manufactured nanoparticles to induce cellular toxicity according to an oxidative stress paradigm, Nano Lett., 2006, 6(8), 1794-1807.

61 T. Xia, M. Kovochich, M. Liong, J. I. Zink and A. E. Nel, Cationic polystyrene nanosphere toxicity depends on cell-specific endocytic and mitochondrial injury pathways, ACS Nano, 2008, 2, 85-96.

62 W. Song, L. Popp, J. Yang, A. Kumar, V. S. Gangoli and L. Segatori, The autophagic response to polystyrene nanoparticles is mediated by transcription factor EB and depends on surface charge, J. Nanobiotechnol., 2015, 13, 87, DOI: 10.1186/s12951-015-0149-6.

63 E. Efeoglu, M. A. Maher, A. Casey and H. J. Byrne, Label-free, high content screening using Raman microspectroscopy: the toxicological response of different cell lines to aminemodified polystyrene nanoparticles (PS-NH(2)), Analyst, 2017, 142(18), 3500-3513, DOI: 10.1039/c7an00461c.

64 H. W. Chiu, T. Xia, Y. H. Lee, C. W. Chen, J. C. Tsai and Y. J. Wang, Cationic polystyrene nanospheres induce autophagic cell death through the induction of endoplasmic reticulum stress, Nanoscale, 2015, 7(2), 736-746, DOI: 10.1039/c4nr05509h.

65 J. Doherty and E. H. Baehrecke, Life, death and autophagy, Nat. Cell Biol., 2018, 20(10), 1110-1117, DOI: 10.1038/ s41556-018-0201-5.

66 E. Janda, A. Lascala, C. Carresi, M. Parafati, S. Aprigliano, V. Russo, C. Savoia, E. Ziviani, V. Musolino, F. Morani, C. Isidoro and V. Mollace, Parkinsonian toxin-induced oxidative stress inhibits basal autophagy in astrocytes via NQO2/quinone oxidoreductase 2: Implications for neuroprotection, Autophagy, 2015, 11(7), 1063-1080, DOI: 10.1080/15548627.2015.1058683.

67 Z. Jia, H. Zhu, B. R. Misra, J. E. Mahaney, Y. Li and H. P. Misra, EPR studies on the superoxide-scavenging capacity of the nutraceutical resveratrol, Mol. Cell. Biochem., 2008, 313(1-2), 187-194, DOI: 10.1007/s11010-008-9756-y.

68 L. Buryanovskyy, Y. Fu, M. Boyd, Y. Ma, T. C. Hsieh, J. M. Wu and Z. Zhang, Crystal structure of quinone reductase 2 in complex with resveratrol, Biochemistry, 2004, 43(36), 11417-11426.

69 A. Ferraresi, R. Titone, C. Follo, A. Castiglioni, G. Chiorino, D. N. Dhanasekaran and C. Isidoro, The protein restriction mimetic Resveratrol is an autophagy inducer stronger than amino acid starvation in ovarian cancer cells, Mol. Carcinog., 2017, 56(12), 2681-2691, DOI: 10.1002/mc.22711. 